\title{
Fault reactivation mechanisms and dynamic rupture modelling of depletion-induced seismic events in a Rotliegend gas reservoir
}

\author{
Loes Buijze ${ }^{1,3, *}$, Peter A.J. van den Bogert ${ }^{2}$, Brecht B.T. Wassing ${ }^{1}$, Bogdan Orlic ${ }^{1}$ \& Johan ten \\ Veen $^{1}$
}

1 Applied Geosciences, TN0, Princetonlaan 6, 3584 CB Utrecht, the Netherlands

2 Shell Global Solutions BV, Kessler Park 1 (At-126L), 2288 GS Rijswijk (ZH), the Netherlands

3 HPT Laboratory, Faculty of Geosciences, Utrecht University. Budapestlaan 4, 3584 CB, Utrecht, the Netherlands

* Corresponding author. Email: loes.buijze@tno.nl

Manuscript received: 6 February 2017, accepted: 11 September 2017

\section{Abstract}

Understanding the mechanisms and key parameters controlling depletion-induced seismicity is key for seismic hazard analyses and the design of mitigation measures. In this paper a methodology is presented to model in $2 \mathrm{D}$ the static stress development on faults offsetting depleting reservoir compartments, reactivation of the fault, nucleation of seismic instability, and the subsequent fully dynamic rupture including seismic fault rupture and near-field wave propagation. Slip-dependent reduction of the fault's strength (cohesion and friction) was used to model the development of the instability and seismic rupture. The inclusion of the dynamic calculation allows for a closer comparison to field observables such as borehole seismic data compared to traditional static geomechanical models. We applied this model procedure to a fault and stratigraphy typical for the Groningen field, and compared the results for an offset fault to a fault without offset. A non-zero offset on the fault strongly influenced the stress distribution along the fault due to stress concentrations in the near-fault area close to the top of the hanging wall and the base of the footwall. The heterogeneous stress distribution not only controlled where nucleation occurred within the reservoir interval, but also influenced the subsequent propagation of seismic rupture with low stresses inhibiting the propagation of slip. In a reservoir without offset the stress distribution was relatively uniform throughout the reservoir depth interval. Reactivation occurred at a much larger pressure decrease, but the subsequent seismic event was much larger due to the more uniform state of stress within the reservoir. In both cases the models predicted a unidirectional downward-propagating rupture, with the largest wave amplitudes being radiated downwards into the hanging wall. This study showed how a realistic seismic event could be successfully modelled, including the depletion-induced stressing, nucleation, dynamic propagation, and wave propagation. The influence of fault offset on the depletion-induced stress is significant; the heterogeneous stress development along offset faults not only strongly controls the timing and location of a seismic slip, but also influences the subsequent rupture size of the dynamic event.

Keywords: dynamic rupture, fault reactivation, induced seismicity, reservoir depletion, rupture modelling

\section{Introduction}

Since the 1990s, induced earthquakes have been recorded in the Groningen field, located in the northern Netherlands. To date, more than $1000 M>1$ events have been recorded, with the largest event a $M_{\mathrm{w}} 3.6$ in August 2012. Despite the relatively small magnitude of these earthquakes, seismicity in the Groningen field has led to substantial damage to surface infrastructure and housing, with several homes being declared uninhabitable. For future exploitation of the field it is important to study the source mechanisms and controlling parameters of the induced seismicity, so that likely trends in magnitude, stress drop and location may be incorporated in seismic hazard analyses, and potential mitigation strategies can be designed. Here we discuss the past observations and likely mechanisms of depletion-induced seismicity, and we present a method to model the source mechanics of depletion-induced earthquakes, combining static geomechanical modelling of the depletion-induced stress changes in a gas reservoir with fully dynamic modelling of the seismic rupture. We incorporate cohesion as a result of fault healing in the fault strength model. The geomechanical model is applied to a typical fault with a small offset in the northern parts 

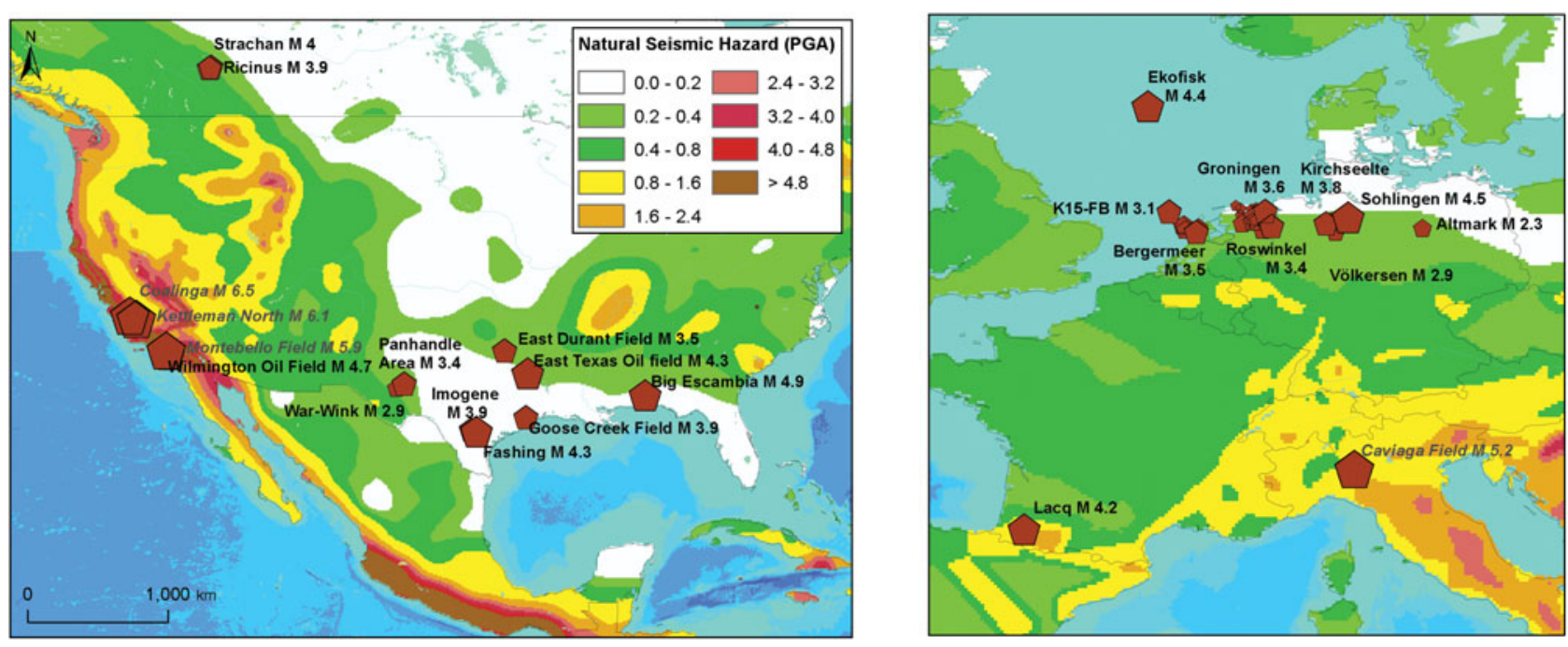

Fig. 1. Instances of depletion-induced seismicity reported in the literature, plotted on a map showing the natural seismic hazard in peak ground acceleration (PGA, m s ${ }^{-2}$ ) with $10 \%$ chance of exceedance in 50 years (Giardini et al., 1999). The legend is the same for both figures. Fields with grey labels have been associated with significant seismicity far below the reservoir.

of the Groningen field. We show how incorporating the fault offset in the geomechanical model leads to enhanced stresses on the fault, earlier nucleation of a seismic event and a reduced seismic rupture length. Additionally, most seismic energy remains in the reservoir formation or is radiated downwards, due to the unidirectional (downwards) propagating rupture and velocity contrasts between formations.

\section{Occurrences of depletion-induced seismicity}

Induced seismicity occurring in (the vicinity of) hydrocarbon fields is not a new phenomenon. In the early 20th century several large, damaging earthquakes may have been related to hydrocarbon production in California (Hough \& Page, 2016). The extremely shallow depth and the proximity to the Inglewood gas field suggest a likely causative link to hydrocarbon production and the Inglewood $M_{\mathrm{w}} 5$ event in 1920. Other events identified by Hough \& Page (2016) likely associated with hydrocarbon production include several events near the Santa Fe Springs oil field (1923, $M \sim 3.5 ; 1929, M_{\mathrm{w}} 5$ Whittier event), and felt shocks in the Long Beach and Richfield oil fields, as well as felt events and surface rupture reported in 1926 for the Goose Creek oil field in the USA (Pratt \& Johnson, 1926). Throughout subsequent decades, numerous cases of hydrocarbon-depletion-induced seismic events were reported in the literature, up to $M>4$. Notable instances include a series of $M<4$ near the Wilmington oil field in California (Kovach, 1974; Yerkes \& Castle, 1976), seismicity near a number of oil and gas fields in Texas (Pennington et al., 1986; Doser et al., 1991), a number of fields in Russia, Uzbekistan and Turkmenistan (Kouznetsov et al., 1995), and the Lacq gas field (M > 4) in southern France (Grasso \& Wittlinger, 1990). The first seismic event in the Netherlands was recorded by the Royal Netherlands Meteorologial Institute (KNMI) in 1986. Since then, seismicity has been recorded in more than 30 Dutch gas fields (Van Thienen-Visser et al., 2012; KNMI, 2015), with the Groningen field producing by far the most events. Felt seismicity is also occurring in several German gas fields, which are part of the same hydrocarbon basin (Leydecker, 2003). There are a few cases where very large events occurred at depths $10-20 \mathrm{~km}$ below the reservoir. In 1976 and 1984 several $M_{\mathrm{s}} \sim 7$ events were recorded below the Gazli gas field in Uzbekistan, in a region previously observed to be aseismic (Eyidogan et al., 1985; Plotnikova et al., 1996). A number of $M>5$ earthquakes occurred below oil fields in California, possibly induced by stress changes related to the hydrocarbon mass removal from the fields (Segall, 1985). In both cases stress changes at these long distances from the reservoir are expected to be small, e.g. for the Coalinga field in California the net stress change on the fault may have been 0.05 MPa (Segall, 1985), a fraction of the coseismic stress drop.

The locations and magnitudes of depletion-induced events reported in the literature to date are summarised in Figure 1. Most depletion-induced events occurred in sedimentary basins, which generally have a low natural seismicity rate.

\section{Mechanisms of depletion-induced seismicity}

When a porous rock formation is depleted, the pore pressure declines, which causes compaction and stress changes within the reservoir formation and in the surroundings. This is known as poro-elastic stressing. These stress changes act on, and can potentially reactivate, pre-existing faults (pre-existing planes of weakness) that are ubiquitous throughout the earth's crust. Stress changes occur:

i. inside the reservoir. As the pore pressure decreases, the effective vertical stress is increasing (i.e. becomes more compressive) and the volume of the reservoir rock is decreasing. Vertically, compaction of the reservoir rock is mostly 
A

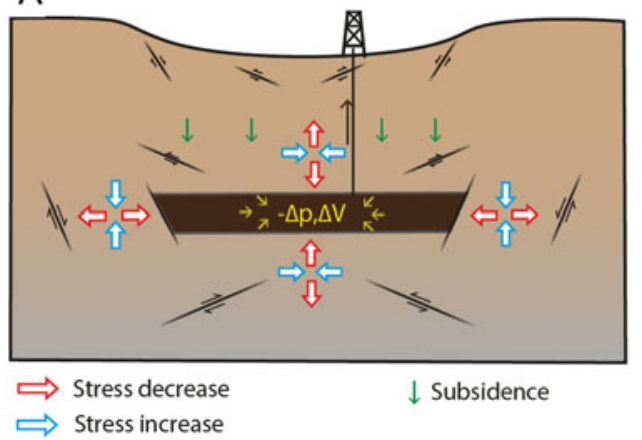

B

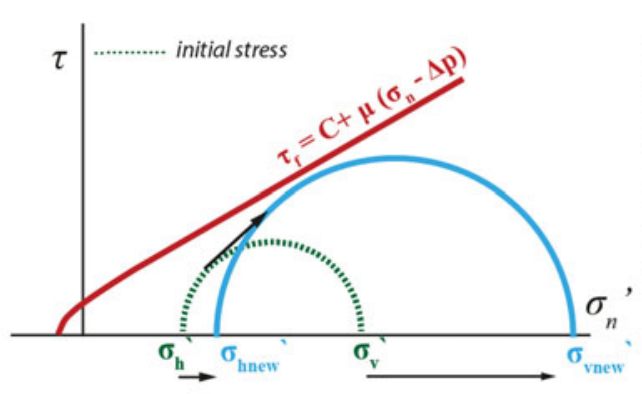

C

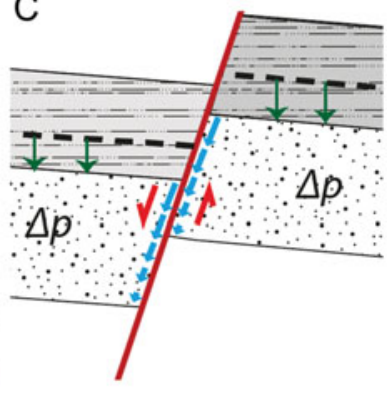

Fig. 2. (A) Illustration of poro-elastic stress changes and promoted faulting mechanisms outside of a depleting reservoir (redrawn after Segall et al., 1998).

(B) Effective stress development inside a laterally extensive depleting reservoir undergoing uniaxial compaction, shown for an unstable stress path (arrow). The initial stress state is shown by green dashed semicircle, and the state in depleted reservoir by a blue semicircle. (C) Sketch of differential compaction across a fault.

accommodated through subsurface deformation and ground subsidence. The total vertical stress change above a laterally extensive reservoir is therefore nearly zero. This means that the effective vertical stress increase is equal to the pore pressure decrease $\left(\Delta \sigma_{\mathrm{v}}{ }^{\prime}=-\Delta p\right)$. Horizontally, however, the reservoir is coupled to the rock volume outside of it; hence the volume change will lead to a reduction in total horizontal stress and a smaller increase in the effective horizontal stress $\left(\Delta \sigma_{\mathrm{h}}{ }^{\prime}=-\Delta p v /(1-v)\right)$. As a result, the differential stress in the reservoir increases. This may bring faults within the reservoir closer to failure depending on the Poisson's ratio, which is one of the factors that influence the magnitude of $\Delta \sigma_{\mathrm{h}}{ }^{\prime}$ (Fig. 2A,B): the lower the Poisson's ratio, the steeper the reservoir stress path and larger the potential for depletion-induced fault reactivation (e.g. Hettema et al., 2000; Van den Bogert, 2015).

ii. outside the reservoir. Due to elastic coupling between the reservoir and the surrounding rock, the stresses around the reservoir will also be perturbed. The volume reduction of the reservoir rock in the horizontal direction also leads to a decrease in total horizontal stress beside the reservoir, and stress transfer from the shrinking reservoir (stress arching) to the surroundings increases the vertical stress on the sides just beyond the reservoir, both promoting normal faulting to the sides of the reservoir. Directly above the reservoir the lateral shrinking of the reservoir may cause increased horizontal stresses and decreased vertical stresses, promoting thrust or reverse faulting (Fig. 2A). An additional effect may be elastic unloading below the reservoir due to the removal of mass (Segall, 1985).

For simple reservoir geometries (e.g. discs, rectangular reservoirs) the poro-elastic stress changes mentioned above can be calculated analytically (Geertsma, 1973; Segall, 1989; Segall et al., 1994). However, hydrocarbon fields are often structurally complex, folded and faulted. To analyse the depletion-induced stress changes in complex structural settings, more complex (numerical) modelling is required. Studies analysing differential compaction of reservoir compartments separated by a fault (compaction on both sides of the fault is not equal, causing relative slip motions of opposite sign across the fault; Fig. $2 \mathrm{C}$ ) showed that significant stress concentrations developed along that fault, in particular when offset along the fault was present (Roest \& Kuilman, 1994; Nagelhout \& Roest, 1997; Mulders, 2003; Orlic \& Wassing, 2013; Van den Bogert, 2015). Hence the effect of fault geometry on stress development is thought to play an important role in generating the seismicity in the Groningen field.

\section{Modelling of depletion-induced seismicity}

Many of the earlier modelling studies on fault reactivation in compacting reservoirs mentioned in the previous section have used elasto-plastic fault behaviour, where, after the depletioninduced stresses have exceeded the Mohr-Coulomb failure criterion, sliding on the fault is accommodated with a constant friction coefficient. The slip on the fault and expansion of the area of slip can only be increased by further depletion-induced stressing.

In reality, the strength of the fault may drop (rapidly) after exceeding peak strength, causing increased stress transfer to neighbouring areas and expansion of the slipping zone. Depending on the fault-weakening parameters, the slip on the fault can accelerate and grow outside of the nucleation area without further depletion. During a rapid reduction in strength, seismic waves may be generated. A number of more recent studies have incorporated fault-weakening behavior to model (depletion-) induced slip on faults (Wassing et al., 2014; Zbinden et al., 2017). Here fault slip was calculated in a quasi-static manner, i.e. inertial effects are not taken into account and wave propagation is not modelled. In this study we model fault weakening and seismic slip in a fully dynamic calculation (Cappa \& Rutqvist, 2012; Buijze et al., 2015a,b). For wave propagation the fully dynamic 
calculation is always required, but for fault slip and the reactivated fault area a fully dynamic (computer-intensive) analysis may to a first order $(\sim 10 \%)$ be similar to fault slip modelled in a quasi-static (less intensive) analysis (Wassing et al., 2016). Further research into the differences between quasi-static and fully dynamic modelling of induced seismicity is ongoing. Here we computed fully dynamic rupture induced by depletion, and compared a model with an offset fault to a model without offset on the fault, showing the large effect of the presence of an offset on the stresses and rupture on the fault.

\section{Field observations and model set-up}

We use a 2D plane strain model approach and DIANA Finite Element (FE) software v10.1(DIANA, 2016) to simulate fault reactivation, nucleation and seismic slip on a normal fault crosscutting seven stratigraphic formations corresponding to the Rotliegend reservoir and over- and underburden. The model is similar to the model for depletion-induced seismicity presented in Buijze et al. (2015a), but is more focused on the specific formations, fault geometries and field data from the Groningen field. Besides a more detailed lithology, the model uses different weakening parameters, focused on the cohesion rather than friction. In the following sections we present the model geometry and set-up and discuss the choice of input parameters on which the FE model was based.

\section{Lithologies, fault geometries, and seismicity observed in the Groningen field}

Figure 3 presents the stratigraphy of the reservoir formation and over- and underlying formations as encountered in the Stedum 01 well (SDM-01) (www.nlog.nl). In this well in the north of the Groningen field (Fig. 4A) a borehole array is currently monitoring induced seismicity; another borehole array was placed in the Zeerijp well. The main reservoir rock in the Groningen field is the Slochteren Formation, a sequence of fluvial and aeolian sandstones intercalated with silty claystones which belongs to the late Permian Upper Rotliegend Group. Towards the top also conglomerates and breccias are encountered. The thickness of the Slochteren in SDM-01 is $200 \mathrm{~m}$, but the thickness varies across the Groningen field from $100 \mathrm{~m}$ in the south to $\sim 250 \mathrm{~m}$ in the north. In the Groningen field the Slochteren Formation is overlain by claystone of the Ten Boer Member of the Silverpit Formation, also belonging to the Upper Rotliegend Group, which contains sandstone streaks that may also be subjected to depletion. The thickness of the Ten Boer ranges from $\sim 20 \mathrm{~m}$ in the southeast to $80 \mathrm{~m}$ in the northwest of the field; at the SDM-01 well it is $65 \mathrm{~m}$. The depth of the top of the Upper Rotliegend Group lies between 2600 and $3000 \mathrm{~m}$ (Fig. 4A). The Ten Boer Member is overlain by the Upper Permian Zechstein Group. The base of the Zechstein Group consists of a $50 \mathrm{~m}$

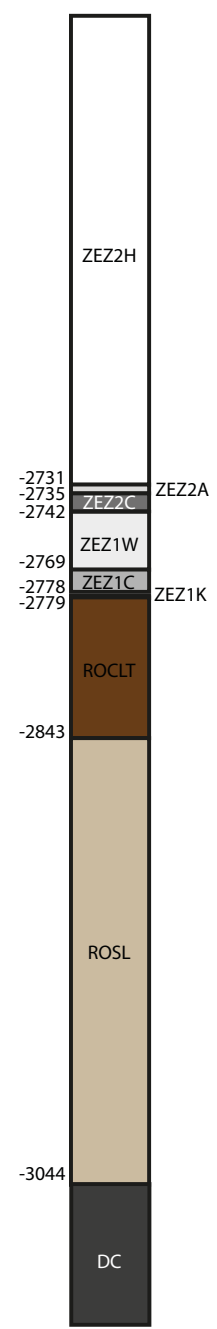

ZEZ2H Salt Member: Mainly halite, continues to $-2155 \mathrm{~m}$

ZEZ2A Basal Anhydrite Member: relatively pure anhydrite body

ZEZ2C Z2 Carbonate Member: Finely laminated, argillaceous limestone

ZEZ1W Z1 Anhydrite Member: Massive anhydrite, potentially containing dolomite stringers

ZEZ1C Z1 Carbonate Member:Transitioning from argillaceous limestone at the base to anhydrite at the top

ZEZ1K Coppershale Member: 0.5 - $1 \mathrm{~m}$ thick brown black shale

ROCLT Ten Boer Clay Member: Red-brown, sandy clay- and siltstone interval, occasionally containing sandstone stringers

ROSL Slochteren Formation: Sandstones and conglomerates, sometimes intercalated with clay layers

DC Limburg Group: Grey-black fine-grained siliciclastic sediments commonly intercalated with coal seams. Also sand bodies are present in this formation.

Fig. 3. Stratigraphy in the northwestern part of the Groningen field, taken from the Stedum 1 (SDM-01) well (www.nlog.nl), with nomenclature and lithostratigraphic description from www.dino-loket.nl. See also Figure 4 for well location. Depths are in true vertical depth $(m)$.

thick sequence of anhydrites and carbonates. The anhydritecarbonate sequence is overlain by hundreds of metres of predominantly halite. The Slochteren reservoir unconformably overlies the Carboniferous Limburg Group which comprises siliciclastics intercalated with coal seams. The thickness of the Limburg Group below the Groningen field is 700 to over $1500 \mathrm{~m}$.

The Groningen field is characterised by faults of various orientations and dimensions such as length, vertical penetration and fault offset (Fig. 4). The fault dip is generally quite steep, between 65 and $90^{\circ}$ (Wentinck, 2015). Three main fault trends can be recognised: NNW-SSE, E-W and WNW-ESE. The NNW-SSE faults are the longest, and show the largest offset, with a maximum of $600 \mathrm{~m}$ along the faults bounding the reservoir. Most major faults have offsets in the range 50-150 m. Near the SDM-01 and ZRP-01, offsets vary from 25 to $250 \mathrm{~m}$. Also in the southwest some larger offsets were measured. The majority of the smaller $\mathrm{E}-\mathrm{W}$ faults recognised from the seismic data have smaller offsets 

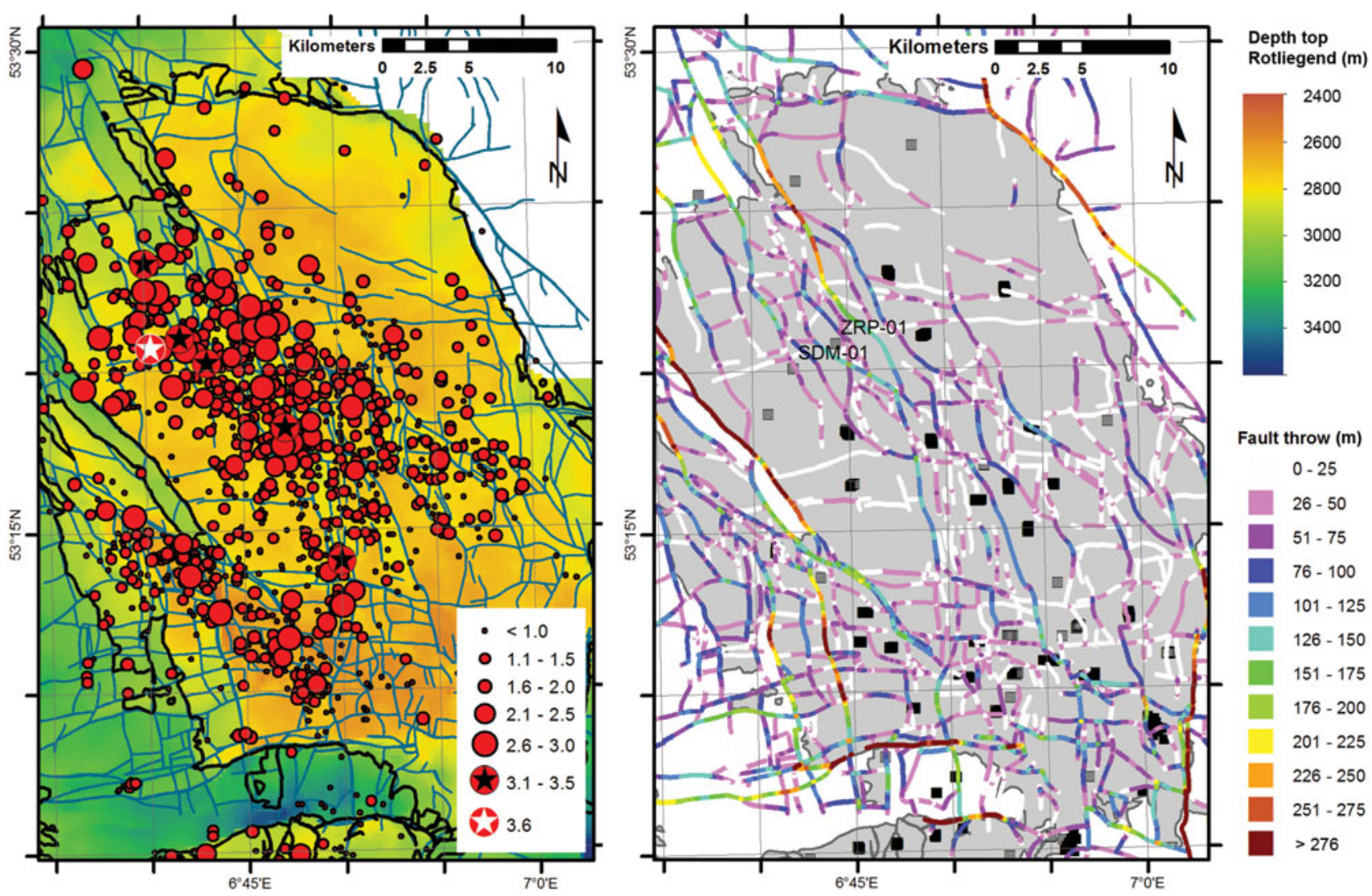

Fig. 4. (A) Groningen field (black outline) coloured with depth of the top of the Rotliegend formation (www.nlog.nl). Faults imaged in the top of the Rotliegend are shown as the turquoise lines (www.nam.nl). Seismic events recorded by the KNMI since 1986 are shown by the red circles (www.knmi.nl, seismic catalogue retrieved 30 May 2017). The largest event (12 August $2012 M_{w}$ 3.6) is indicated by the white starred red circle, events with M 3.1-3.5 are indicated by the black starred red circle. (B) Faults in the Groningen field (grey) coloured by fault offset (www.nam.nl). Black squares indicate producing wells (including those with an imposed production cap), grey squares closed-in wells. The Stedum 1 (SDM-01) well and the Zeerijp 1 wells are labelled; at these wells borehole seismometers are in place at reservoir depth.

between 0 and $50 \mathrm{~m}$. Considering these offsets and the formation thicknesses, the top Slochteren sandstone may be juxtaposed against the Ten Boer Member and the (basal) Zechstein Group. Figure 5 presents a field example of a mesoscale fault (offset $\sim 10 \mathrm{~m}$ ) in the Rotliegend and the Basal Zechstein Formation in the Harz Mountains in Germany. The Basal Zechstein is much thinner than observed in the Groningen field well logs, and the Ten Boer Member is absent here, but the photograph shows how the base of the Zechstein may be juxtaposed against Rotliegend sandstone by the fault offset. The fault from the outcrop was filled with cataclastic, quartz-rich material (Fig. 5D). The outcrop also shows that the transitions between formations may be very sharp (Fig. 5C).

The first seismicity in the Groningen field was recorded in 1991, more than 30 years after the start of production in 1959. Since then over 1000 events have been recorded, with the largest event a $M_{\mathrm{w}} 3.6$ in August 2012 (see Fig. 4B). Most seismicity occurred in the northwest part of the field, followed by the southwest (Fig. 4A); the southeast and northeast show significantly less (recordable) seismicity. For a detailed analysis of the seismicity through time, and the spatio-temporal relationship with production and compaction we refer the reader to e.g. Bourne et al. (2015), Van Thienen-Visser (2015) and Spetzler \& Dost (2017).

\section{Model geometry and elastic parameters}

We based our geomechanical model on the stratigraphy as encountered in the northwestern parts of the field, summarising the SDM-01 litho-stratigraphy into seven model layers, by combining the ZEZ1K and ZEZ1C members into one layer (Fig. 6). The model dimensions are $4000 \mathrm{~m}$ horizontally by $2000 \mathrm{~m}$ vertically. The overburden above a depth of $2500 \mathrm{~m}$ was not included in the model, to reduce the model size and computational time. Instead we applied a loading boundary condition to simulate the overburden weight. The model must be wide enough so that the influence of the boundary conditions does not significantly influence the calculated stress and induced deformation slip on the fault. A comparison of an $8000 \mathrm{~m}$ wide model containing an offset fault to a $100000 \mathrm{~m}$ wide model showed that the differences in stress after depletion between both models were no larger than $0.7 \%$ of the depletion pressure (Mulders, 2003). For 

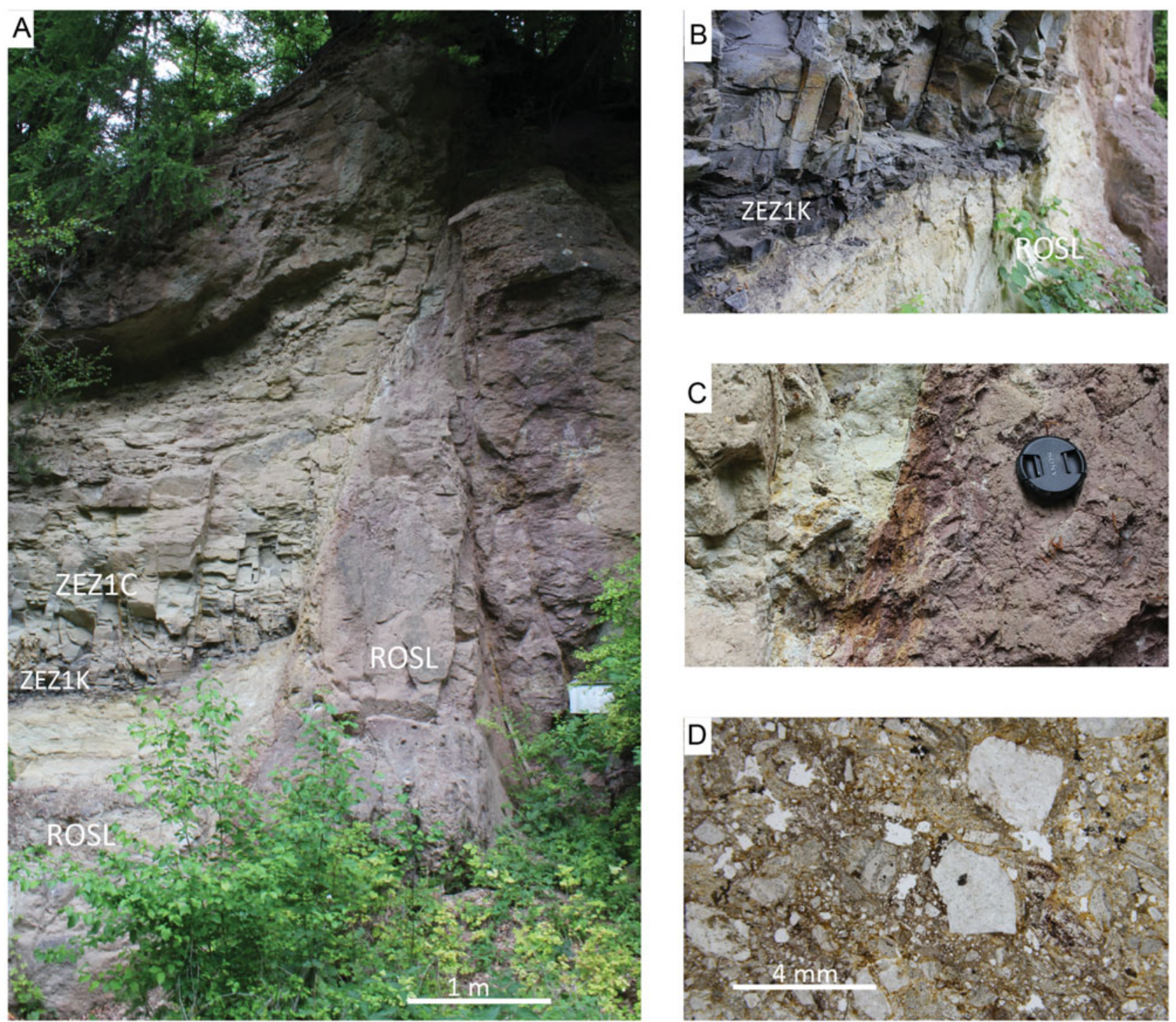

Fig. 5. (A) Normal fault with a $\sim 10 \mathrm{~m}$ offset in the upper Rotliegend (ROSL) Formation and base of the Zechstein Formation, Münden Quarry, Germany. The Coppershale Member (ZEZ1K) and the basal Zechstein carbonate sequence including 'stinky dolomite' are present (ZEZ1C) above the upper Rotliegend (note that the Ten Boer Member is not present at this locality). (B) Contact of (bleached) Rotliegend sandstone in the hanging wall with the overlying Coppershale Member. (C) Fault contact between bleached Rotliegend sandstone just below Rotliegend-Zechstein interface and the red Rotliegend sandstone in the footwall (right). (D) Micrograph of brecciated material in/very close to the fault surface.

the narrower model used in our study we expect stress differences on the order of $1 \%$ of the total depletion pressure. We evaluated the difference between extending the upper bound of the model to the free surface and simulating the overburden by applying a load boundary condition. We find the models with the load boundary to have $0.04 \mathrm{MPa}$ larger horizontal stress. Stress differences related to the model boundaries are relatively minor. Increasing the model size further would be at the cost of resolution on the fault, which would lead to poorer resolution of dynamic fault slip.

The formations were modelled with linear plane strain elements (i.e. assuming a very long reservoir in the out-of-plane direction), and the fault was modelled with interface elements for which we can specify elastic and fault frictional parameters (see 'Fault friction and weakening through slip-dependent loss of cohesion' below). To ensure good resolution, the element size along the fault was set to $1 \mathrm{~m}$, coarsening further away from the fault up to a size of $25 \mathrm{~m}$. Elastic parameters Young's modulus $E$ and Poisson's ratio $v$ in the Slochteren Formation depend strongly on porosity. Here, for simplicity, we adopted a single value for $E$ of $15 \mathrm{GPa}$, a $v$ of 0.1 and a density of $2450 \mathrm{~kg} \mathrm{~m}^{-3}$ consistent with a porosity of $\sim 15-20 \%$ (Lele et al., 2015). The elastic parameters for the Slochteren and the other formations are summarised in Table 1. Note that the elastic parameters used here are static parameters; the acoustic Young's modulus retrieved from sonic logs may be twice as high (Wentinck, 2015). 


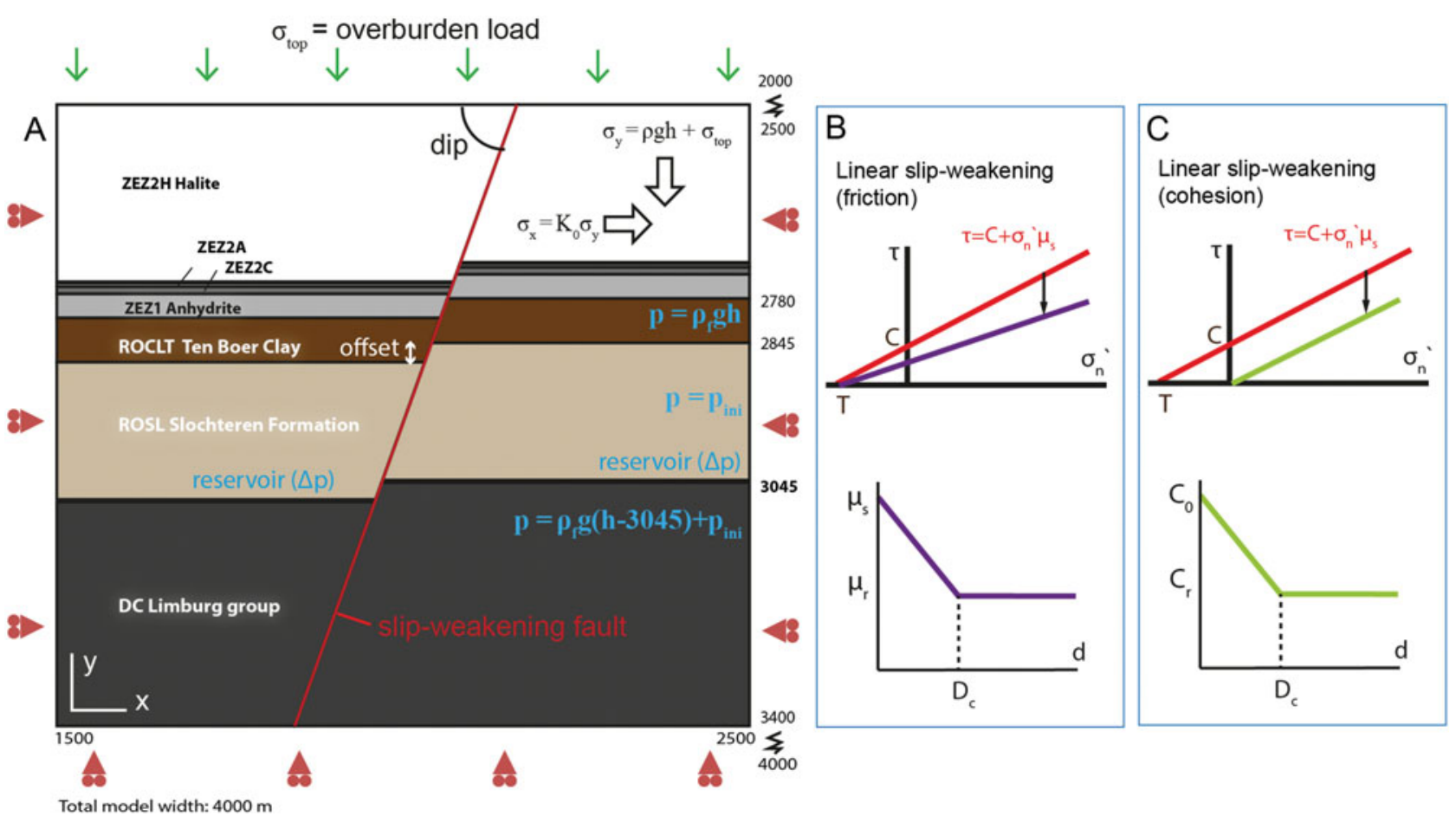

Fig. 6. (A) Model geometry and central part of the finite element mesh in DIANA FEA. A $70^{\circ}$ dipping fault offsets the stratigraphy (in this study, offset is 0 or $50 \mathrm{~m}$ ). The sides and base are supported by roller boundaries, and a top load is applied to simulate the overburden weight. (B) Mohr-Coulomb friction criterion for the interface elements modelling the fault, with a linear reduction in friction coefficient with inelastic shear displacement on the fault. (C) Mohr-Coulomb failure criterion for the interface elements modelling the fault with a linear reduction in cohesion $C$ with inelastic shear displacement on the fault. $D_{c}$ is the critical slip distance over which weakening occurs.

Table 1. Input parameters for model formations. The depth is specified for the hanging wall of the offset fault.

\begin{tabular}{llllllll}
\hline Formation & $\begin{array}{l}\text { Top } \\
\text { depth }(\mathrm{m})\end{array}$ & $\begin{array}{l}\text { Base } \\
\text { depth }(\mathrm{m})\end{array}$ & $\begin{array}{l}\text { Thickness } \\
(\mathrm{m})\end{array}$ & $\begin{array}{l}\text { Young's } \\
\text { modulus (GPa) }\end{array}$ & $\begin{array}{l}\text { Poisson } \\
\text { ratio (-) }\end{array}$ & $\begin{array}{l}\text { Density } \\
\left.\mathbf{k g ~ m}^{-3}\right)\end{array}$ & $\begin{array}{l}\mathbf{K}_{\mathbf{0}} \\
(-)\end{array}$ \\
\hline ZEZ2H Halite & -2000 & -2730 & 730 & 35 & 0.35 & 2150 & 1 \\
ZEZ2A Basal Anhydrite & -2730 & -2735 & 5 & 65 & 0.3 & 2900 & 0.9 \\
ZEZ2C Carbonate & -2735 & -2745 & 10 & 35 & 0.3 & 2700 & 0.9 \\
ZEZ1 Anhydrite + Carbonates -2745 & -2780 & 35 & 65 & 0.3 & 2900 & 0.9 \\
ROCL Ten Boer & -2780 & -2845 & 65 & 20 & 0.1 & 2500 & 0.72 \\
ROSL Slochteren & -2845 & -3045 & 200 & 15 & 0.1 & 2500 & 0.72 \\
DC Limburg & -3045 & -4200 & 1155 & 25 & 0.2 & 2700 & 0.72 \\
\hline
\end{tabular}

A $70^{\circ}$ dipping normal fault was included, cross-cutting the formations, in agreement with the commonly observed steep faults in the Groningen field. As mentioned in the introduction, the fault offset has a large effect on the stress development on that fault and in the reservoir. We chose a fault offset of $50 \mathrm{~m}$, within the range found near the SDM-01 well (see previous section). We compare the results to a $0 \mathrm{~m}$ offset scenario to emphasise the differences.

\section{Initial state of stress}

The total vertical stress $\sigma_{\mathrm{v}}$ is a function of the density and depth $\left(\sigma_{\mathrm{v}}=\rho g h\right)$; a gradient of $21-23 \mathrm{MPa} \mathrm{km}^{-1}$ is common in the north of the Netherlands (van Eijs, 2015). In our model the vertical stress gradient was $22.4 \mathrm{MPa} \mathrm{km}^{-1}$. The pre-depletion minimum horizontal stress is poorly constrained, since no minifrac tests were conducted in the Groningen field prior to the start of production, and mud loss data are unreliable (van Eijs, 2015). During production, two minifrac tests were performed in different wells at different depletion pressure $(\triangle P=15$ and $\Delta P=20 \mathrm{MPa}$ ). These measurements together with mud loss estimations from two other locations did not show a clear trend, making it difficult to constrain the virgin $\sigma_{\mathrm{h}}$ or the evolution of $\sigma_{\mathrm{h}}$ with depletion. We used an in situ total stress ratio $K_{0}=\sigma_{\mathrm{h}} / \sigma_{\mathrm{v}}$ of 0.72 in the base-case model presented in this study, with an average $\sigma_{\mathrm{h}}$ gradient of $16.1 \mathrm{MPa} \mathrm{km}^{-1}$ in 
agreement with other modelling studies (TN0, 2013; Lele et al., 2015; Van den Bogert, 2015). For the Zechstein overburden we assumed all shear stresses have relaxed over geological time due to creep of the halite and anhydrite, and used a $K_{0}$ of 0.9 for the anhydrites and carbonates and 1 for the halite. We have conducted a small number of sensitivity analyses for the $K_{0}$ ratio. An extensive sensitivity analysis is beyond the scope of this paper, but we suggest considering the sensitivity to the stress ratio $K_{0}$ in further analyses dealing with fault reactivation and seismicity in the Groningen reservoir, as was for example done in Buijze et al. (2015a).

\section{Initial pore pressure and pressure depletion}

The initial reservoir pressure in the Slochteren Formation is $35 \mathrm{MPa}$, which is overpressurised with respect to the hydrostatic pore pressure like many fields in the north of the Netherlands (Verweij et al., 2012). For the overlying formations we imposed a hydrostatic pressure gradient, in the reservoir an initial uniform pressure $p_{\text {ini }}$ of $35 \mathrm{MPa}$, and for the underburden also a hydrostatic gradient was imposed, but with an additional $5 \mathrm{MPa}$ created by the overpressure in the reservoir. History matching of the pressures in the field suggests most faults are not (fully) sealing, except those with very large offsets predominantly in the west and northwest (NAM, 2016). Hence for our $50 \mathrm{~m}$ offset fault scenario we assumed the pressure in the Slochteren Formation decreases uniformly over the entire formation during depletion, with the fault elements bounding the reservoir exhibiting the same initial pressure and pressure decrease as the reservoir. The reservoir pressure and depletion pressure were also imposed in fault elements juxtaposing Slochteren against Limburg or Slochteren against Ten Boer. No depletion occurred in the Ten Boer and the underburden in the current model. The assumptions of pressure and pressure diffusion in the fault influence fault reactivation and slip; we will address this in the discussion.

\section{Fault friction and weakening through slip-dependent loss of cohesion}

The fault interface elements have a shear and normal stiffness which allow elastic deformation along the interface. Assuming the fault zone is thin, elastic displacements on the fault should be very small compared to deformation in the surrounding formations. To achieve this the stiffness should be as high as possible without inhibiting convergence in the model. Here we have set the interface stiffness to 10 times the shear modulus $G$ of the surrounding formation; stiff enough to limit elastic deformation on the fault but not so stiff that the calculation becomes unstable. In addition to the fault stiffness, the shear strength $\tau_{\mathrm{f}}$ of a fault can be expressed by the Mohr-Coulomb criterion, which is governed by the cohesion $C$ and the friction coeffi- cient $\mu$ multiplied by the effective normal stress $\sigma_{\mathrm{n}}{ }^{\prime}$ (Fig. 4B). The $\mu$ depends on the fault rock lithology; however, faults in the Rotliegend and surrounding formations are rarely cored. Outcrop studies and fracture analysis showed that fault cores in Rotliegend sandstone consist of cataclastic material, fault gouge and breccia (Ligtenberg et al., 2011; see also Fig. 6D). The studied fractures show evidence of cementation with anhydrite cement (Ligtenberg et al., 2011). Some research has also suggested that salt may have intruded the fault zones (BOA, 1993). Analogue models show how salt from the Zechstein Formation could intrude in dilatant brittle fractures created in the stiff basal anhydrites and carbonates, forming patches of salt along the fault (Urai et al., 2016). This is supported by finite difference models showing how creep of salt (in particular on offset faults) leads to a strong reduction in normal stress in the underlying formations (Wassing et al., 2017). In our model the stiff basal Zechstein rocks are underlain by $65 \mathrm{~m}$ of Ten Boer clay, a more ductile rock type. It is uncertain whether dilatant fractures are likely to form in a fault through such a ductile formation, and whether salt could intrude. For the current study we have therefore assumed no salt intrusion has occurred and the fault zone in the reservoir was filled with cataclastic quartz-rich material.

The coefficient of friction $\mu_{s}$ of Rotliegend fault gouge in the in situ conditions was 0.6 (Hunfeld, 2015), in range with measurements on other quartz-rich fault gouges at normal stresses of $\sim 25-35 \mathrm{MPa}$, temperatures of $75-115^{\circ} \mathrm{C}$ and slow slip rates between 0.5 and 0.7 (Chester, 1994; Tembe et al., 2010; Samuelson \& Spiers, 2012). The $\mu_{\mathrm{s}}$ of the Basal Zechstein, Ten Boer and Carboniferous under in situ conditions were 0.7, 0.4 and 0.40.5 respectively (Hunfeld, 2015). Hence for the fault within the Slochteren sandstone we use a $\mu_{\mathrm{s}}$ of 0.6 , for the Limburg (Carboniferous) 0.5, for the fault within the Ten Boer 0.4 and within the basal Zechstein 0.7. Cohesion $C$ is often ignored in studies of natural earthquake behaviour. However, at the relatively low normal stresses at the reservoir depth, cohesion may contribute significantly to fault strength. Experiments have shown that healing of fault gouge materials occurs under hydrothermal conditions, re-strengthening the gouge during the healing period (i.e. as cohesion increases, the failure line in Figure $6 \mathrm{~B}$ and $\mathrm{C}$ would move up). When re-shearing the healed gouge, the strength gained in the healing period may also be lost (via unstable sliding); the longer the healing time, the greater the re-strengthening and the greater the stress drop after re-shearing (Muhuri et al., 2003; Yasuhara et al., 2005; Tenthorey \& Cox, 2006). Under sufficiently long healing times the refracturing of healed gouge may be similar to fracturing of intact rock, e.g. analogous to fracturing an intact rock cylinder in a triaxial experiment (Reches, 1999). On faults in Groningen, which have been inactive for a significant time, significant cementation and healing may have occurred and cohesion may thus not be zero. Quartz cementation in Permian sandstone faults was observed in reservoirs with a 
Table 2. Input parameters for fault.

\begin{tabular}{|c|c|c|c|c|c|}
\hline Formation & $\begin{array}{l}\text { Friction } \\
\text { coefficient } \mu_{\mathrm{s}}(-)\end{array}$ & $\begin{array}{l}\text { Cohesion } \\
\text { C initial (MPa) }\end{array}$ & $\begin{array}{l}\text { Cohesion } C_{2} \\
\text { final at } D_{\mathrm{c}}\end{array}$ & $\begin{array}{l}\text { Critical } \\
\text { distance } D_{c}(\mathrm{~mm})\end{array}$ & $\begin{array}{l}\text { Friction drop } \\
\text { over } D_{\mathrm{c}} \Delta \mu\end{array}$ \\
\hline Fault Slochteren & 0.6 & 3 & 0 & 5 & 0.05 \\
\hline Fault Limburg & 0.5 & 3 & 0 & 5 & 0.05 \\
\hline Fault Ten Boer & 0.4 & 1 & 0 & 1.7 & 0.05 \\
\hline Fault Anhydrite/carbonate & 0.7 & 3 & 0 & 5 & 0.05 \\
\hline
\end{tabular}

burial depth exceeding $2000 \mathrm{~m}$ and is enhanced in small-grained cataclastic fault materials (Fisher et al., 2000). We chose an intermediate value of $C=3 \mathrm{MPa}$ for our base-case scenario, which is $\sim 50 \%$ of the cohesion measured on intact porous sandstones (7-9 MPa) from the nearby Ameland field (Hol et al., 2015). For the clay-rich Ten Boer we assigned a lower cohesion of $1 \mathrm{MPa}$ (see Table 2 for an overview of fault friction and cohesion).

For the post-failure behaviour of the reactivated fault, a form of strength reduction must be prescribed. A sudden reduction in strength lies at the basis for the seismic behaviour that we observe; as the strength drops sufficiently fast, the fault starts sliding rapidly, driven by the elastic energy stored in the surrounding medium, and part of the energy related to the drop in strength is released in the form of seismic waves. Most rupture models use a slip (e.g. linear slip-weakening; Fig. 6B) or slip-rate and time dependent friction coefficient (rate-and-state friction) with zero cohesion. In the current model set-up the fault has cohesion due to fault healing. This cohesion must be (partly) lost upon reactivation, but very little research has been done on exactly how cohesion is removed with fault slip. Experiments show how the strength gained through healing (mostly cohesion) is removed over a certain amount of inelastic slip (e.g. Muhuri et al., 2003). Similar to the linear slip weakening friction we assumed cohesion dropped linearly from its initial value to its residual value ( 0 in this case) over a slip distance $D_{c}$ (Fig. 6C). Simultaneously, frictional weakening occurred on the fault. decreasing the friction with 0.05 from its initial value $\mu_{\mathrm{s}}$. The parameter $D_{\mathrm{c}}$ and how it upscales is one of the major questions in earthquake science. Here we have chosen a $D_{c}$ of $5 \mathrm{~mm}$ such that the fracture energy $G$ related to the generation of new surface related to grain fracturing $\left(1 / 2\left(\tau_{\mathrm{p}}-\tau_{\mathrm{r}}\right) D_{\mathrm{c}}\right.$, where $\left.\tau_{\mathrm{p}}-\tau_{\mathrm{r}}=\Delta C+\Delta \mu \sigma_{\mathrm{n}}\right)$ is $\sim 10^{5} \mathrm{~J} \mathrm{~m}^{-2}$. This is in agreement with $G$ measured for earthquakes with slip of a few $\mathrm{mm}$ to a few $\mathrm{cm}$ (Nielsen et al., 2016), which is the slip typically measured in Groningen earthquakes (Kraaijpoel \& Dost, 2013). We stress that the specific effects of cohesion (in combination with friction) on fault strength, fracturing and unstable sliding have barely been studied in the laboratory, and hence the input parameters are uncertain. However, the stress drop and fracture energy for the current weakening parameters roughly match the observations.

\section{Model procedure and output parameters}

The vertical stress is initialised by applying a gravitational load (overburden weight) to the model, so that $\sigma_{\mathrm{v}}=\rho g h$. Part of the overburden weight is simulated by a constant load boundary condition at the top of the model, which is added to the gravitational load. The stress ratio $K_{0}$ (see Table 1 for $K_{0}$ of different formations) is then applied and equilibrium is calculated in the model (displacements computed to obtain equilibrium are removed after the equilibration). The stiffnesses of the formations were assumed constant during the initialisation phase to prevent the development of artificial stress concentrations at formation boundaries. After initialisation, the different elastic properties (Table 1) were assigned to the different formations. The pore pressures were prescribed in all formations, and the Slochteren Formation was then depleted uniformly over the entire reservoir volume. The changes in the effective and total stresses in and around the reservoir were then calculated in a nonlinear static analysis. These stress changes potentially reactivate the fault and cause (aseismic) sliding to occur on one or more elements. Once a patch of a critical size is slipping, instability occurs in the static model, signifying the onset of seismic slip; no further depletion is possible at that point without stress release. The concept of such a critical fault length (critical nucleation length) follows from the theory of linear weakening (Uenishi \& Rice, 2003). At that moment the analysis was switched from a static analysis to a fully dynamic timedependent analysis including inertial effects, where the seismic slip event and the near-field wave propagation were computed (time step $0.1 \mathrm{~ms}$ ).

Both fault normal and shear stresses may be changing during depletion; to conveniently describe the net effect on the stability of the fault element the Shear Capacity Utilisation (SCU) is used:

$$
\mathrm{SCU}=\frac{\tau}{\tau_{\max }}=\frac{\tau}{C+\left(\sigma_{\mathrm{n}}-P\right) \mu}
$$

When the SCU is $<1$ the failure strength of the fault element has not yet been reached and the element is responding elastically; when it is 1 the fault element has reached the failure criterion and deforms (slips) plastically; when it is 0 no shear stress is present. Shear slip during seismic rupture $d_{\mathrm{f}}$ denotes the relative 

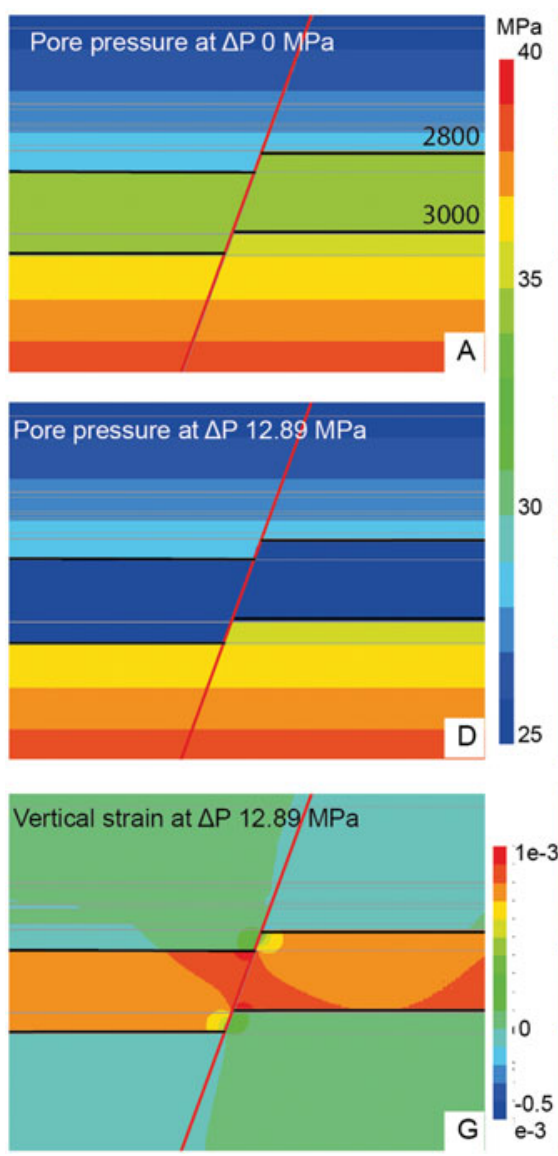

Fig. 7. Model results of stresses, displacements and vertical strains in the formations in a zoomed-in region around the $50 \mathrm{~m}$ offset fault. In the initial conditions (OMPa depletion): (A) pore pressure, (B) effective horizontal stress, (C) effective vertical stress. At $12.89 \mathrm{MPa}$ depletion, at the start of seismic instability: (D) pore pressure, (E) effective horizontal stress, (F) effective vertical stress, (G) vertical strain, (H) horizontal displacements, (I) vertical displacements. Stress units are in $M P a$, displacement units in $\mathrm{mm}$.

displacement of the two formations adjacent to the fault with respect to each other. Similarly, the slip rate $v_{\mathrm{f}}$ indicates the relative velocity at which the two adjacent formations move with respect to each other.

\section{Results}

\section{Stress development on the $50 \mathrm{~m}$ offset fault during depletion of the Slochteren Formation}

The stresses were initialised in the model according to the procedure described in the previous section. For the offset fault scenario, formations with different $K_{0}$ (e.g. 0.72 in the Ten Boer vs 1 in the Zechstein) were juxtaposed against each other across the fault. To obtain initial equilibrium, the $K_{0}$ near the fault deviated from the imposed $K_{0}$ value at the boundaries. This is evident in the irregularities in the initial stress field in the nearfault area in Figure 7B and C, and also in the heterogeneous initial normal and shear stresses on the fault (purple line in Fig. $8 \mathrm{~B}$ and $\mathrm{C}$ ). Small peaks in the initial stress can be observed near the formation boundaries (Fig. 8). In the Zechstein Formation at depths shallower than $2780 \mathrm{~m}$ the normal stress was high and the shear stress is zero due to the imposed high stress ratio $K_{0}$ of 1 . This also means the SCU (see equation 1 ) was also close to zero and the reactivation potential in the Zechstein was very low. Where Zechstein was juxtaposed against Ten Boer clay (2780-2845 m), the $\sigma_{\mathrm{n}}{ }^{\prime}$ was still high (23 MPa), but lower than for the Zechstein-Zechstein juxtapositions (30-32 MPa). Where Ten Boer was juxtaposed against the reservoir (2845-2895 m) $\sigma_{\mathrm{n}}{ }^{\prime}$ is $\sim 18-22 \mathrm{MPa}$, which corresponded to a SCU of 0.5-0.6. The initial $\sigma_{\mathrm{n}}{ }^{\prime}$ in the reservoir was $\sim 15 \mathrm{MPa}$, and the initial shear stress $\tau$ was $6 \mathrm{MPa}$, which places the reservoir at a SCU of 0.5 . The SCU of the underburden was similar at 0.55 .

With depletion the reservoir compacted, causing stress changes within and outside of the reservoir (Fig. 7). After a depletion $\Delta p$ of $12.89 \mathrm{MPa}$, instability occurred in the model, indicating the onset of seismic slip. The effective horizontal stress $\sigma_{\mathrm{h}}{ }^{\prime}$ within the reservoir had increased by $\sim 2 \mathrm{MPa}$, and the effective vertical stress $\sigma_{\mathrm{v}}{ }^{\prime}$ increased by an amount equal to the pore pressure change ( $\Delta p 12.89 \mathrm{MPa}$; Fig. $7 \mathrm{D}-\mathrm{F}$ ). The stress change was uniform up to $200 \mathrm{~m}$ from the offset fault; closer to the fault 

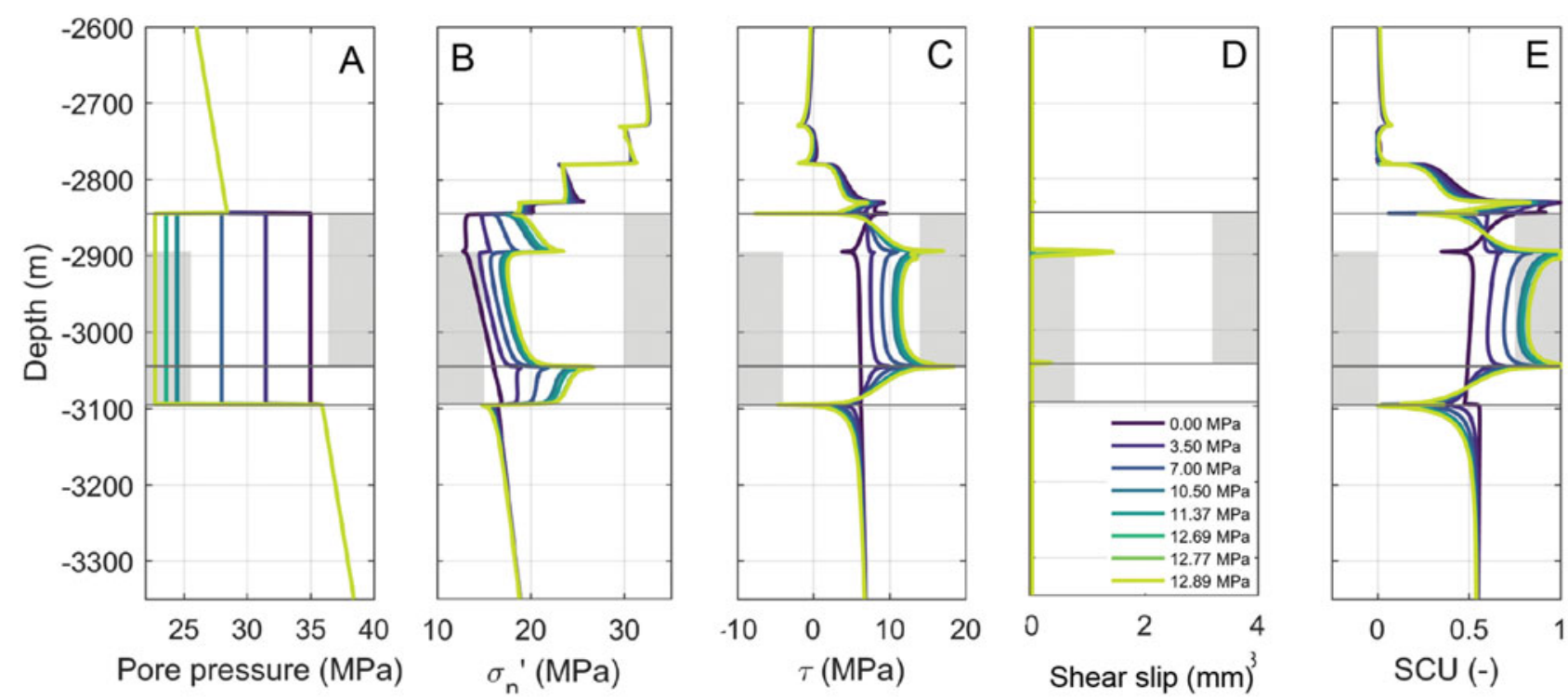

Fig. 8. On-fault data during depletion of the reservoir and initiation of aseismic slip. (A) Pressure in the reservoir. The pressure decrease $\triangle P$ is indicated by the different colours, with dark blue as the pre-depletion situation and yellow after $\Delta P 12.89 \mathrm{MPa}$ of depletion when seismic instability occurs. (B) Effective normal stress, (C) shear stress, (D) (aseismic) shear slip, (E) Shear Capacity Utilisation ( $0=$ stable, $1=$ sliding occurs). The depth interval of the footwall and the hanging wall of the Slochteren Formation is indicated by the grey areas on respectively the right and the left. The coloured lines indicate the amount of pressure decrease $\Delta P$ (see legend in (D)).

the stress state became different, because the fault does not yet accommodate any deformation (it is still locked). Stresses were relatively large near the top of the hanging wall and base of the footwall, and relatively small near the base of the hanging wall. Increased vertical strain builds up near the fault, in particular where Slochteren was juxtaposed against Slochteren (Fig. 7G). The overburden subsided with $0.14 \mathrm{~m}$, equal to the maximum compaction of the reservoir, and across the offset fault a gradient in vertical displacement formed (Fig. 7I).

Both the $\sigma_{\mathrm{n}}{ }^{\prime}$ and $\tau$ increased with $5 \mathrm{MPa}$ with ongoing depletion in the reservoir depth interval (Fig. 8B,C). The net effect was a more critical state of stress on the fault in the reservoir interval as is shown by the high SCU of $0.8-1$ at a $\Delta p$ of 12.89 MPa (Fig. 8E). The largest increase in SCU was observed at the top of the hanging wall and the base of the footwall; stress concentrations formed at the top of the hanging wall and base of the footwall, increasing nearly twice as much as in the reservoir centre. At the top of the Ten Boer overlying the hanging wall (2795-2845 m) the SCU decreased. This fault segment was thus not the most critically loaded part under depletion conditions. Also, just below the reservoir (3045-3100 m), the SCU decreased (because the shear stress decreases) so much that it almost became negative, which indicates a tendency to reverse faulting. Hence destabilisation occurred predominantly where reservoir was juxtaposed against reservoir. Reactivation first occurred at the top of the hanging wall at $10 \mathrm{MPa}$ depletion, and aseismic slip starts to occur (Fig. 8C). The aseismically slipping patch expands with continued depletion until the critical nucleation length is reached and instability occurs, signifying the onset of seismic rupture at 12.89 MPa depletion. The maximum aseismic slip at that point was just below $2 \mathrm{~mm}$.

\section{Seismic rupture on the offset fault}

Slip on the fault started to accelerate from the nucleation site, the highly stressed zone at the top of the hanging wall at $\sim 2895 \mathrm{~m}$ depth. The expanding rupture propagated predominantly downwards into the reservoir (Fig. 9A). The seismic event propagated only $\sim 20 \mathrm{~m}$ into the overlying Ten Boer Member and was then arrested because it encountered the low shear stress in the Ten Boer that formed during depletion. Downwards propagation of the rupture front accelerated until $0.18 \mathrm{~s}$ due to the favourable large shear stresses in the reservoir interval. The stress drop (difference in shear stress before and after the rupture) in the reservoir was $\sim 2 \mathrm{MPa}$ (Fig. $9 \mathrm{C}$ ). The largest slip rates occurred near the front of the downward-propagating rupture. Figure $9 B$ and $C$ show how the shear stress increases in front of the propagating rupture, bringing those parts of the fault closer to failure. Maximum slip rates of almost $1.3 \mathrm{~m} \mathrm{~s}^{-1}$ were attained after $0.015 \mathrm{~s}$, achieving a maximum shear slip of $47 \mathrm{~mm}$ in the reservoir. At $0.18 \mathrm{~s}$ the downwards-propagating rupture was arrested at a depth of $3045 \mathrm{~m}$, at the base of the hanging wall. The shear stress on the fault below the reservoir was lowered during depletion, and during the rupture it was therefore too far from critical for the rupture to propagate. A lot of energy would be required to propagate further into this region, because the fault must first be brought to failure before it can slip. For larger dynamic cohesion and/or friction drops, events are more likely to 

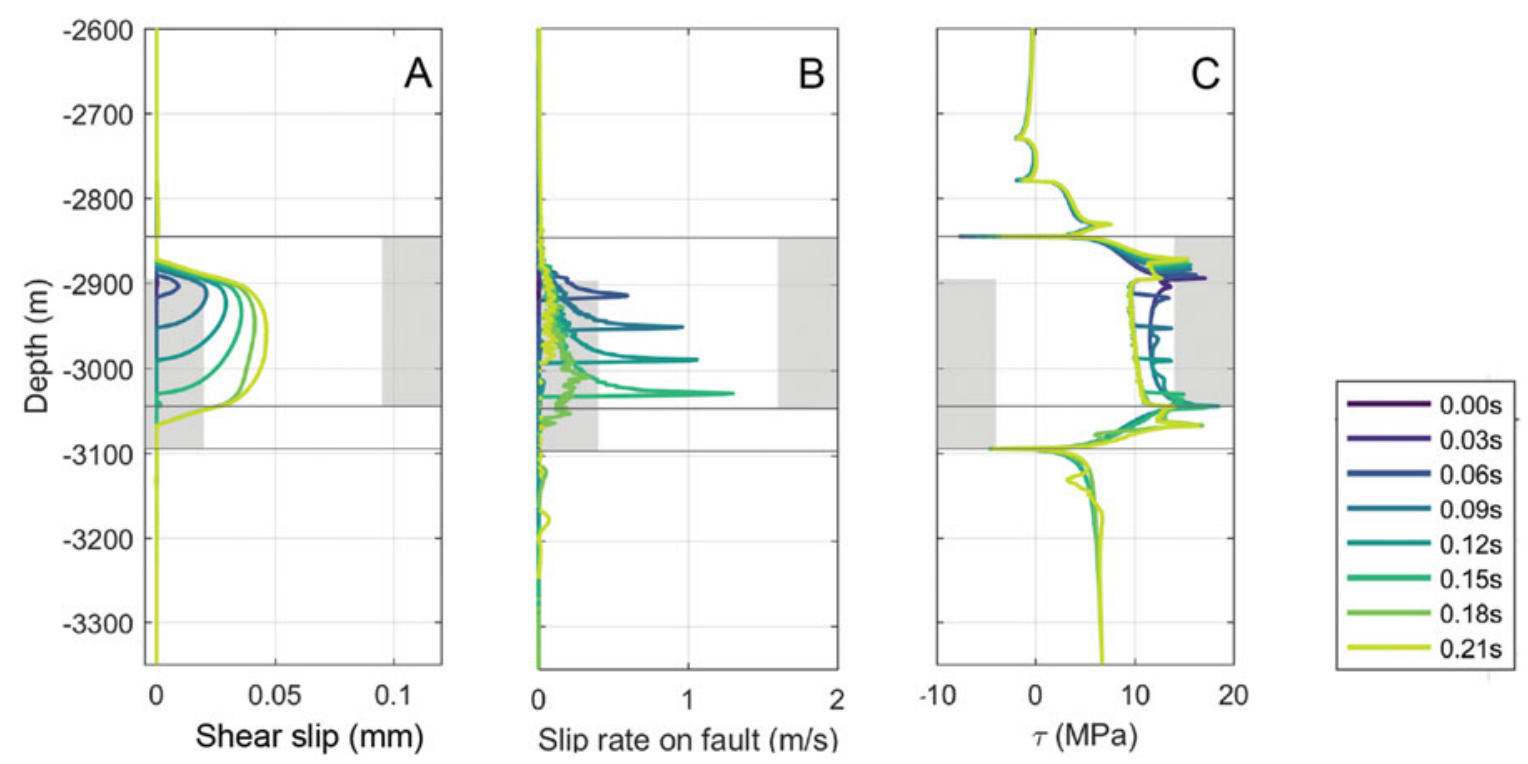

Fig. 9. Seismic slip on the $50 \mathrm{~m}$ offset fault $\left(70^{\circ} \mathrm{dip}\right)$. (A) Relative shear slip along the fault; positive is in the downdip direction. (B) Slip rate on the fault. (C) Shear stress during dynamic rupture. The shear stress at $t=0$ is the shear stress developed during depletion of the reservoir (see also Fig. 8 ). Coloured lines indicate the time from the start of seismic rupture. The grey blocks to the sides indicate the depth interval of the hanging wall (left) and the footwall (right).
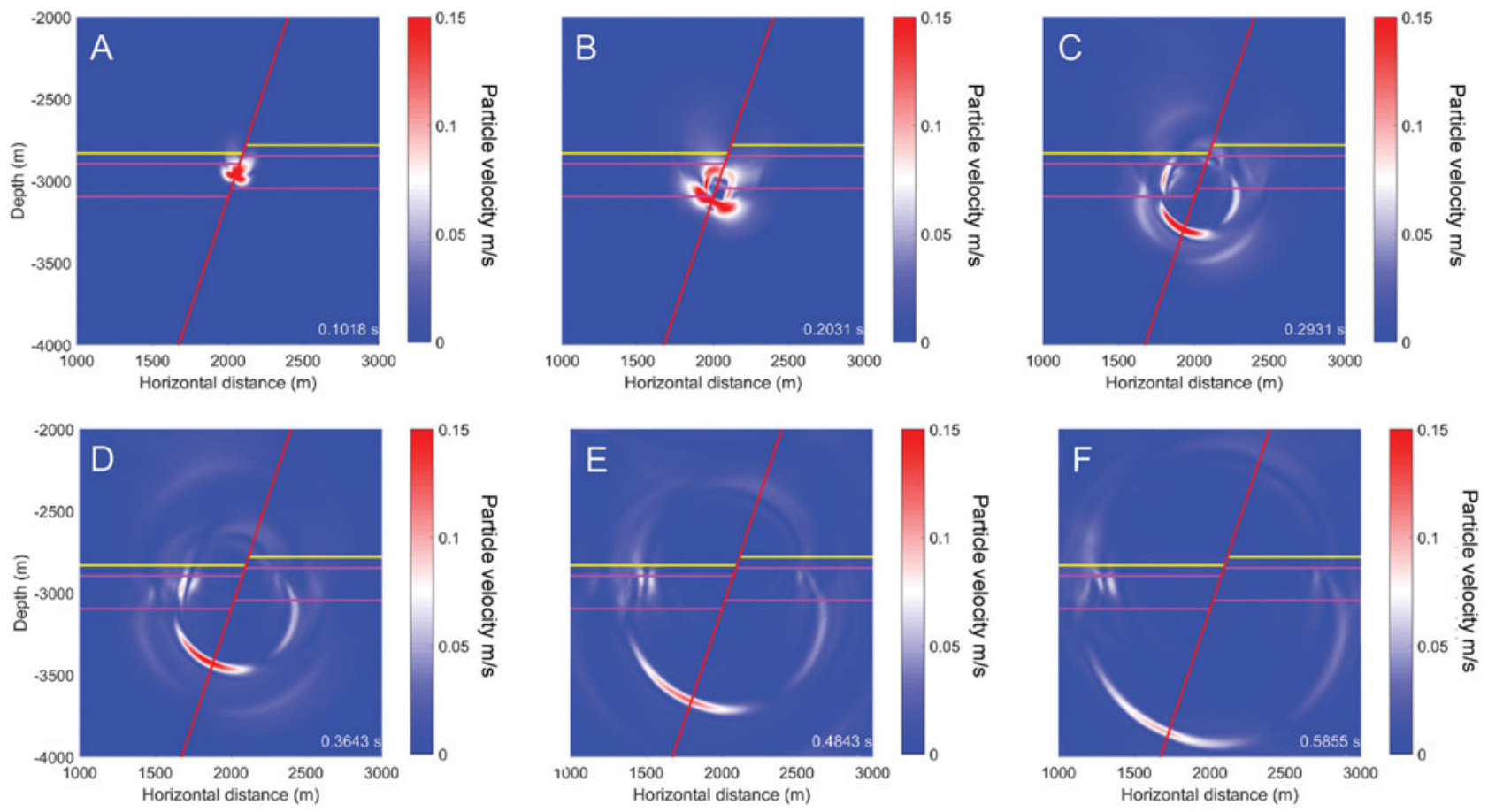

Fig. 10. Wave propagation following the seismic event on the $50 \mathrm{~m}$ offset fault. The snapshots illustrate different points in time counting from the start of the dynamic rupture phase (see bottom right). The colour scale indicates the particle velocity in the formations flanking the fault (red line). The top and base of the Slochteren are indicated by the pink lines, the top of the Ten Boer Member (base of the Zechstein) by the yellow line.

propagate downwards. Alternatively, if the in situ shear stress was more critical, further propagation can occur (see further next section).

Figure 10 shows the particle velocities in the formations. During the seismic event the particle velocities in the formation directly adjacent to the slip patch were large, since the fault was slipping at $>1 \mathrm{~m} \mathrm{~s}^{-1}$ (Fig. 10A). After $0.2 \mathrm{~s}$, slip on the fault had stopped but radiated waves continued to propagate downwards (Fig. 10B) with amplitudes in the order of $\mathrm{dm} \mathrm{s}^{-1}$. The downward-propagating radiated wave amplitudes were much 

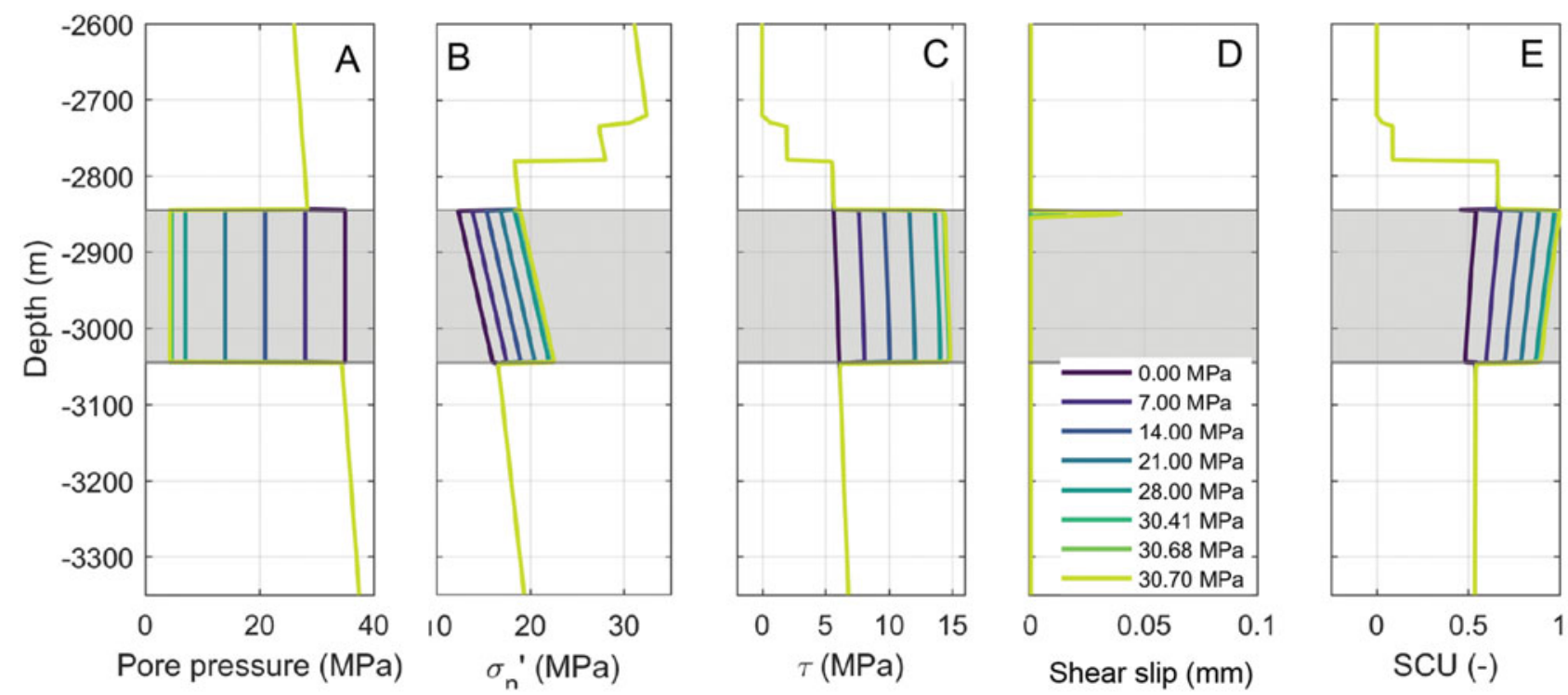

Fig. 11. On-fault results as a function of reservoir depletion $\Delta p$ (legend of $\Delta p$ is shown in (D)) on a $0 \mathrm{~m}$ offset $70^{\circ}$ dipping fault cross-cutting the reservoir. (A) pressure, (B) effective normal stress, (C) shear stress, (D) (aseismic) shear slip, (E) Shear Capacity Utilisation ( $0=$ stable, $1=$ sliding occurs). The depth interval of the Slochteren Formation is indicated by the grey area. The coloured lines indicate the amount of pressure decrease.

larger than those propagating upwards, because of the unidirectional (downward) directivity of the rupture as observed in Figure 9A and B. Figure 10D-F show how higher-amplitude waves also became trapped in the low-velocity Slochteren en Ten Boer Formation. The velocity contrast of the Ten Boer with the basal Zechstein was large, and waves travelled along the boundary in the reservoir or were reflected.

\section{Comparison to a reservoir without offset: compaction and seismic rupture}

The stress state on the fault was very different for a reservoir cross-cut by a fault without offset (Fig. 11). Both the $\sigma_{\mathrm{n}}{ }^{\prime}$ and $\tau$ increased with depletion, but the increase in stress occurs only within the reservoir interval and was relatively uniform; no peaks in stress formed near the formation boundaries. The SCU was largest near the top of the reservoir, starting at a level of 0.5. Fault reactivation first occurred at $\triangle P 29 \mathrm{MPa}$, much later than the offset fault reactivated at $\Delta P 12.46 \mathrm{MPa}$. Seismic instability occurred at $\triangle P 30.70 \mathrm{MPa}$. The fault stresses just below and above the reservoir did not change due to the absence of offset. The difference in stress build-up between the $0 \mathrm{~m}$ and $50 \mathrm{~m}$ offset scenarios is clear when comparing the stress paths (Fig. 12). The stress path for the $0 \mathrm{~m}$ offset scenario followed the analytical solution for poro-elastic stressing in a laterally extensive, uniaxially compacting reservoir (e.g. Hettema et al., 2000). However, the stress path in the $50 \mathrm{~m}$ offset scenario was much steeper, reaching failure at much lower depletion pressures. Figure 12 also shows that if cohesion is present on the fault the timing of reactivation will be influenced significantly, because the angle between stress paths for realistic Poisson's ra-

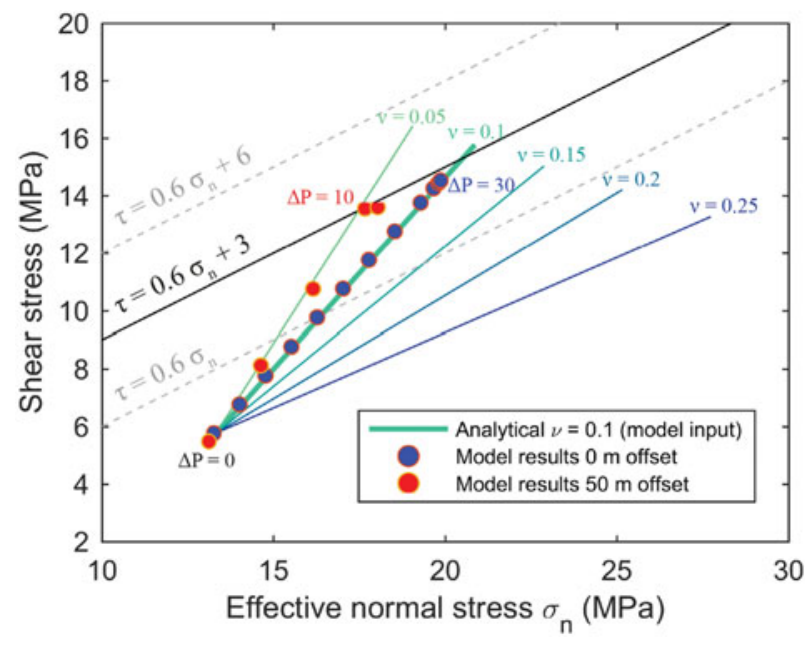

Fig. 12. Stress paths as a function of reservoir depletion at $2900 \mathrm{~m}$ depth for the $0 \mathrm{~m}$ offset and $50 \mathrm{~m}$ offset fault models, and comparison to the analytically calculated stress path for uniaxial compaction in a laterally extensive reservoir depleting from 35 to $0 \mathrm{MPa}$ (initial stresses and pressure, stress ratio $K_{0}=0.72$ and Poisson's ratio $v=0.1$ are same as used in the numerical models). Analytically calculated stress paths for different $v(0.05-0.25)$ are shown for reference. The failure criterion as used in the numerical models ( $\mu=0.6, C=3 \mathrm{MPa})$ is shown in black, and two other failure lines with different $C$ are depicted with grey dashed lines. The stress path for the $50 \mathrm{~m}$ offset reservoir is steeper than for $0 \mathrm{~m}$ offset due to local stress concentrations along the offset fault.

tios and the failure lines for a $\mu$ of 0.6 is small. As the failure line moves up due to the presence of cohesion, convergence of the stress path to the failure line will take significantly more depletion. 

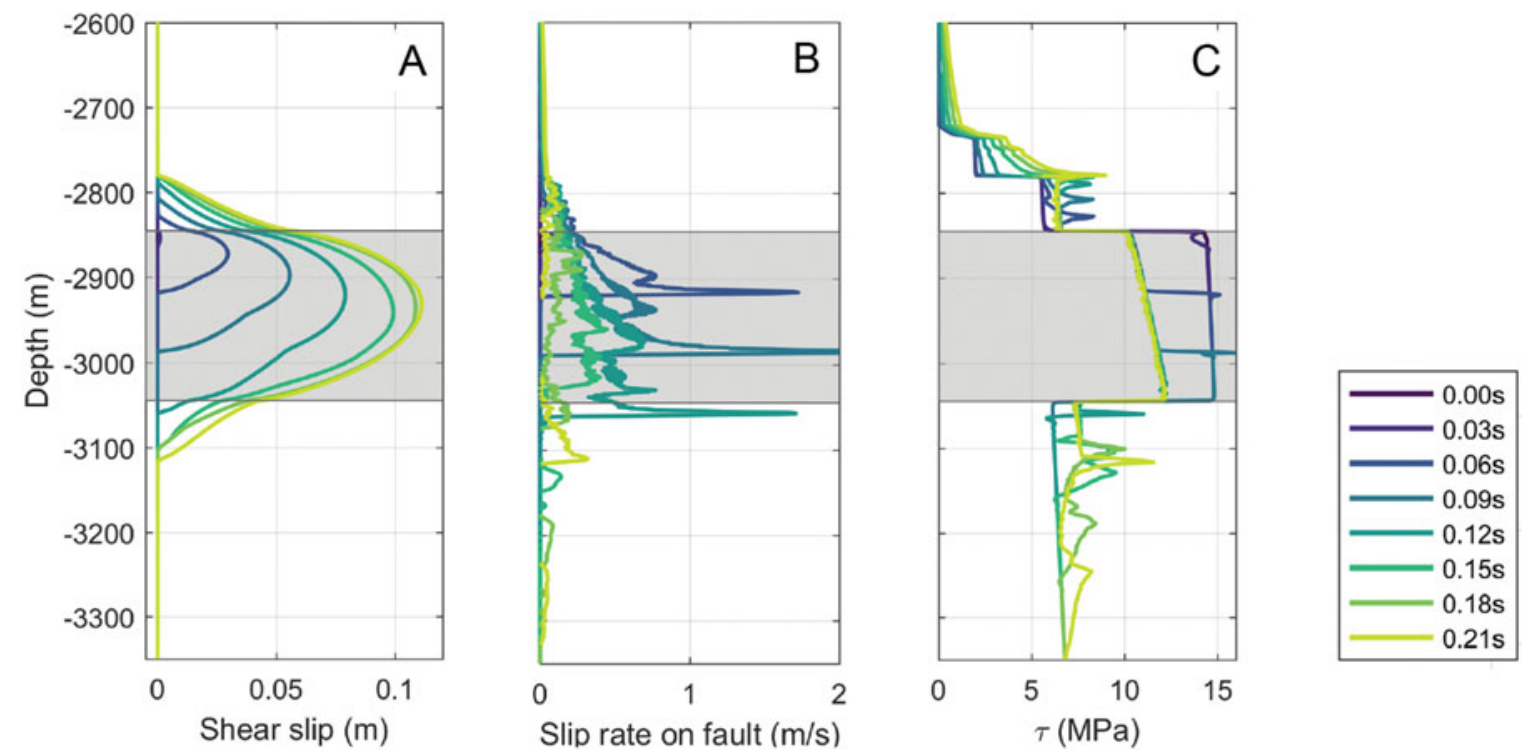

Fig. 13. Seismic slip on the fault without offset $\left(70^{\circ} \mathrm{dip}\right)$. (A) Relative shear displacement along the fault, positive is in the downdip direction. (B) Slip rate on the fault. (C) Shear stress during seismic rupture. The grey blocks indicate the depth interval of the reservoir formation.

The relatively uniform shear stresses that developed during depletion (in contrast to the more peaked stress on a $50 \mathrm{~m}$ offset fault) also had a profound effect on the propagation of rupture. The uniform, near-critical state of stress across the reservoir interval and the several MPa stress drop favoured downward propagation of rupture until entering the less critically stressed underburden. The slip rate on the fault was much larger than for the offset fault scenario (up to 3 vs $1.8 \mathrm{~m} \mathrm{~s}^{-1}$ ), and the total length of the fault that slipped and the maximum slip were much larger than for the offset fault scenario. The entire reservoir interval slipped seismically, and the rupture event expanded for $\sim 50 \mathrm{~m}$ into the Ten Boer and underburden. No low shear stress region had formed above and below the reservoir (as in the $50 \mathrm{~m}$ offset case), making it easy for rupture to propagate outside of the reservoir. The rupture did decelerate when entering the underburden which has a low SCU; during weakening the shear stress did not fall below the stress in the underburden (negative stress drop) and too much energy is required to propagate the seismic event further.

In Figure 14 the $0 \mathrm{~m}$ and $50 \mathrm{~m}$ offset cases are compared for various in situ stress ratio $K_{0}$. The pressure required for reactivation is much higher for the $0 \mathrm{~m}$ offset scenario as discussed in this section, and is also more sensitive to the $K_{0}$. Above a $K_{0}$ of 0.72 , reactivation did not occur for $0 \mathrm{~m}$ offset. For the $50 \mathrm{~m}$ offset, reservoir fault reactivation occurred from the most critical $\mathrm{K}_{0}(0.68)$ up to the most stable $K_{0}$ evaluated (0.79). The pressure required for reactivation increased with $K_{0}$ from 7 to $18 \mathrm{MPa}$. The slip patch length (length of the fault that slipped seismically) in a $0 \mathrm{~m}$ offset reservoir was large compared to a $50 \mathrm{~m}$ offset reservoir, propagating several hundreds of metres into the underburden depending on the $K_{0}$. For the $50 \mathrm{~m}$ offset case, ruptures remained mostly confined to the reservoir interval. At the most stable $K_{0}$ of $0.75-0.79$, only part of the reservoir was reactivated seismically; rupture remained confined to the high shear stress region that formed at the top of the hanging wall (see also Fig. 8).

\section{Discussion}

In this study we show how the seismic source of depletioninduced earthquake can be simulated, including reservoir depletion, nucleation of seismic rupture, and subsequent near-field wave propagation by dynamic fault slip. A seismic rupture was modelled that propagated downwards on an offset fault, from the top of the hanging wall halfway through the reservoir. The model procedure presented in this paper opens up many links with field data, such as sizes, location and static stress drops of recorded events, but (due to the fully dynamic analysis) also with waveforms recorded in the two downhole monitoring arrays present in the field. Here we discuss several of the assumptions of the model and implications of the model results.

Large uncertainty exists in the pre-depletion minimum horizontal stress. The in situ stress, in combination with the static friction and/or friction drop on the fault, controls whether events are likely to propagate outside the reservoir or remain within the reservoir interval. We also assumed homogeneous depletion within the Slochteren Formation, without any depletion occurring in the Ten Boer or in the Carboniferous. However, sand lenses may be present within these formations that deplete with a time delay with respect to the reservoir. This will result in a more complex state of stress on the fault, depending on the size of these lenses. Additionally, incorporating the different responses of gas and water in the reservoir 

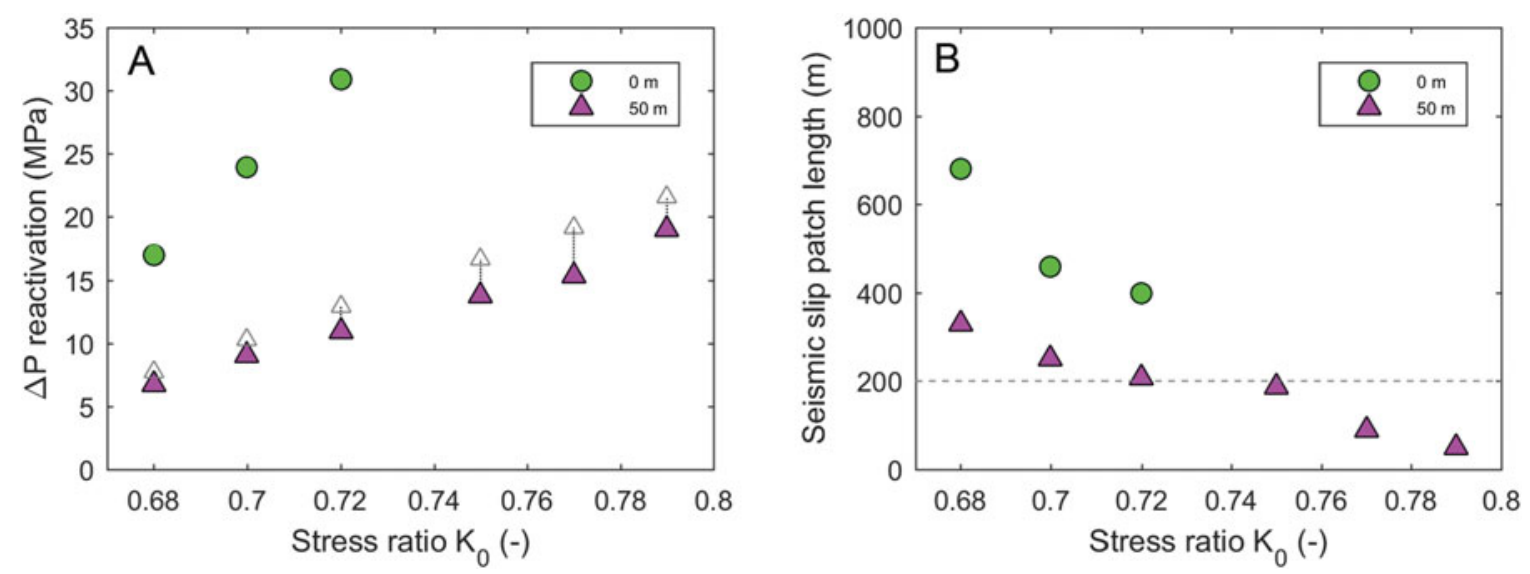

Fig. 14. (A) Sensitivity of pressure required for reactivation to in situ stress ratio $K_{0}\left(\sigma_{h} / \sigma_{v}\right)$. Coloured symbols indicate the pressure change at the first instance of fault reactivation, open symbols connected with the dashed line indicate the pressure change when instability occurred and the seismic event started. (B) Seismic slip patch length (fault length that slipped seismically) as a function of in situ stress ratio $K_{0}$. The thickness of the reservoir (200 $m$ ) is indicated by the dashed line. Magenta triangles: $50 \mathrm{~m}$ offset fault; green circles: $0 \mathrm{~m}$ offset fault.

generates a more complex stress state (Zbinden et al., 2017). Within the Slochteren Formation, compaction may be heterogeneous due to variations in porosity; this can also change the state of stress along the fault. Further modelling is required to determine whether these effects are likely to be minor with respect to the reservoir-scale trend or whether they may play an active role in the nucleation. In addition, recent experimental work has shown that deformation in compacting porous sandstones may be $20-60 \%$ irrecoverable (Hol et al., 2015). This inelastic behaviour may lead to a different evolution of the horizontal stress; future modelling efforts will attempt to include the inelastic behaviour of the reservoir rock, and also of the caprock (salt creep).

It was assumed that depletion occurred evenly throughout the Slochteren Formation. This is supported by the reservoir modelling and history matching, which suggest most faults are not sealing. However, if faults were (partially) sealing, the delayed pressure response would influence fault slip (Zbinden et al., 2017). Diffusion of pressure from the overburden and underburden formations and fault in response to the reservoir depletion would also influence slip. A decrease in pressure in the underburden fault would stabilise the fault, forming a barrier to propagating slip (Zbinden et al., 2017), opposite to the diffusion effect for injection (Buijze et al., 2015b). Depletion of the Ten Boer Member also influences the stress changes, bringing a larger area closer to failure. We recommend that these factors be addressed in future work.

To our knowledge, this is the first study that dynamically models the nucleation and propagation of a seismic event with a cohesion-weakening function. The slip and slip rates modelled in this study are similar to those modelled using purely friction weakening (Buijze et al., 2015a). Dynamic frictional weakening may however be expected during seismic rupture; e.g. thermal pressurisation might occur when rapid slip heats up the fault rock and pore fluids, causing pressure build-up. The weakening mechanisms for relatively small earthquakes like those in Groningen have not been studied in the laboratory, and more research on this topic is recommended. The weakening function also has implications for the timing of seismic events. Any weakening function yields an aseismic slip phase, where the fault is slipping slowly until a critical nucleation length is reached and seismic instability can occur. This means there is a delay between the onset of fault reactivation and the onset of seismic slip, which may be quite large in time since the production and stress build-up in the field take place over decades. The nucleation length depends, among other things, on the inverse of the weakening rate, which in the case of the linear slip weakening is $D_{\mathrm{c}} /\left(\tau_{\mathrm{p}}-\tau_{\mathrm{r}}\right)$ (or in this study $D_{\mathrm{c}} /\left[\Delta C+\Delta \mu \sigma_{\mathrm{n}}\right]$ ) (Uenishi \& Rice, 2003). It is thus important to know the amount of weakening. Also the shape of the weakening function may be of great importance for the nucleation length The exact physical mechanisms governing healing, fracturing and unstable slip on (Groningen-type) faults are still poorly understood, and experiments under appropriate loading and boundary conditions must be conducted to gain a basic understanding of the governing mechanisms of (dynamic) weakening of fault materials relevant to the Dutch subsurface, as proposed in Spiers et al. (2017).

We showed how the geometry of a reservoir offset along a fault can enhance stress changes on that fault and promote seismic slip, in agreement with previous work. For the case without offset (which corresponds to analytical solution for poroelastic stressing inside a laterally extensive, uniaxially compacting reservoir) across the fault, the onset of seismic rupture (or nucleation) only occurred at significant depletion. For a more stable initial stress condition $\left(K_{0}>0.72\right)$ the $0 \mathrm{~m}$ offset fault would require a (significantly) lower friction angle to be reactivated. Offset on faults (less than the reservoir thickness) 
enhances the stress near the top of the hanging wall and base of the footwall, causing reactivation at considerably less depletion than for the $0 \mathrm{~m}$ offset case. The hetereogeneous fault stresses caused by offset not only influenced the onset of slip, but also the size of the induced seismic event. Other offsets cause a different state of stress along the fault, and events nucleate at different levels of depletion depending on the offset (Buijze et al., 2015a; Van den Bogert, 2015). In the Groningen reservoir many different faults are present with different offsets (Fig. 4), which are likely to be reactivated at different points in time, and also generate events of different sizes, giving rise to a lot of variability. Thus far a relationship between fault offset and earthquake occurrence in Groningen has not been straightforward, but many other factors may complicate the onset and size of seismic events, e.g. lithological variability, fault topography (roughness), heterogeneous depletion and compaction, location uncertainty, limited data, etc. The geomechanical modelling approach presented can help in addressing and understanding these effects, and provides many opportunities to link with observations from e.g. borehole seismometers. The geomechanical models indicate that geometry-enhanced stressing effect due to offset cannot be ignored in studies dealing with the timing and location of seismicity in the Groningen field. Additionally, the weakening behaviour $\left(\Delta \tau, D_{\mathrm{c}}\right)$ and the state of stress $K_{0}$ strongly influence the timing and size of events; we recommend that these parameters and their uncertainties be included in future work.

\section{Conclusions}

- The generation of a seismic event in a depleting reservoir was successfully modelled, including depletion-induced stressing, fault reactivation, nucleation, seismic fault rupture and near-field wave propagation

- The rapid loss of cohesion after fault reactivation can lead to seismic instability, similar to purely frictional weakening.

- Depletion caused critical stresses at both the top of the hanging wall and base of the footwall. Under the current modelling assumptions nucleation occurred at the top of the hanging wall.

- Faults which offset depleting reservoir compartments will be reactivated at much lower pressure drops than faults without offset, as the offset locally concentrates the stress build-up.

- Offset creates a more variable stress distribution along the fault, which influences the nucleation and propagation of events with low-stress regions acting as barriers. The zerooffset geometry creates a relatively uniform stress distribution along the fault, which causes reactivation at a much later stage but is more favourable for rupture propagation across the depleting reservoir depth interval.

- The largest-amplitude seismic waves are radiated downwards into the hanging wall, due to the directivity of the rupture (downwards-propagating), and the strong velocity contrasts with the overlying Zechstein Formation.

\section{Acknowledgements}

We thank the two reviewers for their supportive and useful feedback. We also thank our colleagues and acquaintances at TNO, Utrecht University, Shell and NAM for helpful discussions on this subject. We thank NAM for providing the fault data of the Groningen field. Part of the work has been performed within the framework of the M4ShaleGas project, funded by the European Union's Horizon 2020 research and innovation programme under grant agreement number 640715. This work was in part supported by contract number UI49294 awarded to Utrecht University by the Nederlandse Aardolie Maatschappij (NAM) in the framework of the research programme that the company initiated after the ML = 3.6 Huizinge earthquake in 2012 .

\section{References}

BOA (Begeleidingscommissie Onderzoek Aardbevingen), 1993. Eindrapport multidisciplinair onderzoek naar de relatie tussen gaswinning en aardbevingen in Noord-Nederland (Final report on a multidisciplinary study of the relationship between gas production and earthquakes in the northern part of the Netherlands). Royal Netherlands Meteorological Institute (De Bilt).

Bourne, S.J., Oates, S.J., Bommer, J.J., Dost, B., van Elk, J. \& Doornhof, D., 2015. A Monte Carlo method for probabilistic hazard assessment of induced seismicity due to conventional natural gas production. Bulletin of the Seismological Society of America 105(3): 1721-1738.

Buijze, L., Orlic, B. \& Wassing, B., 2015a. Modeling of dynamic fault rupture in a depleting gas field. Final Report. Report No. TN0 2015 R10844. TNO (Utrecht).

Buijze, L., Orlic, B., Wassing, B.B.T. \& Schreppers, G., 2015b. Dynamic rupture modeling of injection-induced seismicity: influence of pressure diffusion below porous aquifers. 49th US Rock Mechanics/Geomechanics Symposium, 1 June-1 July 2015, San Francisco, California, USA. Proceedings

Cappa, F. \& Rutqvist, J., 2012. Seismic rupture and ground accelerations induced by $\mathrm{CO}_{2}$ injection in the shallow crust. Geophysical Journal International 190(3): 1784-1789.

Chester, F.M., 1994. Effects of temperature on friction: constitutive equations and experiments with quartz gouge. Journal of Geophysical Research: Solid Earth 99(B4): 7247-7261.

DIANA, 2016. DIANA 10.1 User Manual 2016. Available at https:/dianafea.com/ manuals/d101/Diana.html.

Doser, D.I., Baker, M.R. \& Mason, D.B., 1991. Seismicity in the War-Wink gas field, Delaware Basin, west Texas, and its relationship to petroleum production. Bulletin of the Seismological Society of America 81(3): 971-986.

Eyidogan, H., Nábělek, J. \& Toksöz, M.N., 1985. The Gazli, USSR, 19 March 1984 earthquake: the mechanism and tectonic implications. Bulletin of the Seismological Society of America 75(3): 661-675.

Fisher, Q.J., Knipe, R.J. \& Worden, R.H., 2000. Microstructures of deformed and non-deformed sandstones from the North Sea: implications for the origins of quartz cement in sandstones. In: Worden, R. \& Morad, S. (eds): Quartz 
cementation in sandstones. International Association of Sedimentologists Special Publication, 29. Blackwell Publishing Ltd (0xford): 129-146.

Geertsma, J., 1973. Land subsidence above compacting oil and gas reservoirs. Journal of Petroleum Technology 25: 734-744.

Giardini, D., Grünthal, G., Shedlock, K.M. \& Zhang, P., 1999. The GSHAP Global Seismic Hazard Map. Annals of Geophysics 42(6).

Grasso, J.R. \& Wittlinger, G., 1990. Ten years of seismic monitoring over a gas field. Bulletin of the Seismological Society of America 80(2): 450-473.

Hettema, M.H.H., Schutjens, P.M.T.M., Verboom, B.J.M. \& Gussinklo, H.J., 2000. Production-induced compaction of a sandstone reservoir: the strong influence of stress path. SPE Reservoir Evaluation and Engineering 3: 342-347.

Hol, S., van der Linden, A.J., Zuiderwijk, P.M.M., Marcelis, F.H.M. \& Coorn, A.H., 2015. Mechanical characterization of Permian reservoir sandstone from the Moddergat-3 well in the Dutch Wadden Area. Report No. SR.15.11614. Shell Global Solutions International B.V. (Rijswijk).

Hough, S.E. \& Page, M., 2016. Potentially induced earthquakes during the early twentieth century in the Los Angeles Basin. Bulletin of the Seismological Society of America 106(6): 2419-2435.

Hunfeld, L., 2015. Frictional properties of simulated fault gouges prepared from lithologies present in the Groningen gas field: an experimental study at in-situ P-T-chemical conditions. (MSc Thesis. Utrecht University (Utrecht). Confidential.

KNMI. (2015). Catalog of induced earthquakes in the Netherlands. Royal Netherlands-

Meteorological Institute (De Bilt). Available at www.knmi.nl/seismologie/ geinduceerde-bevingen-nl.

Kouznetsov, O., Sidorov, V., Katz, S. \& Chilingarian, G., 1995. Interrelationships among seismic and short-term tectonic activity, oil and gas production, and gas migration to the surface. Journal of Petroleum Science and Engineering 13(1): 57-63.

Kovach, R.L., 1974. Source mechanisms for Wilmington 0il Field, California, subsidence earthquakes. Bulletin of the Seismological Society of America 64: 699711.

Kraaijpoel, D. \& Dost, B., 2013. Implications of salt-related propagation and mode conversion effects on the analysis of induced seismicity. Journal of Seismology 17(1): 95-107.

Lele, S.P., Garzon, J.L., Hsu, S.-Y., DeDontney, N.L., Searles, K.H. \& Sanz, P.F., 2015. Groningen 2015 geomechanical analysis. Exxon Mobiel Upstream Research Company, Spring, TX, USA, Final Report. Nederlandse Aardolie Maatschappij (Assen).

Leydecker, G., 2003. Das Erdbeben vom 11. Juli 2002 in Weyhe südlich Bremen in der Norddeutschen Tiefebene. Zeitschrift für Angewandte Geologie 1: 59-64.

Ligtenberg, H., Okkerman, J. \& De Keijzer, M. (2011). Fractures in the Dutch Rotliegend - an overview. In: Grötsch, J. \& Gaupp, R. (eds): The Permian Rotliegend of the Netherlands. SEPM Special Publication, 98. SEPM (Tulsa, 0klahoma, USA): 239-244.

Muhuri, S.K., Dewers, T.A., Scott, T.E. \& Reches, Z., 2003. Interseismic fault strengthening and earthquake-slip instability: Friction or cohesion? Geology 31(10): 881-884

Mulders, F.M.M., 2003. Modelling of stress development and fault slip in and around a producing gas reservoir. PhD Thesis. Technical University of Delft (Delft).
Nagelhout, A.C.G. \& Roest, J.P.A., 1997. Investigating fault slip in a model of an underground gas storage facility. International Journal of Rock Mechanics and Mining Sciences 34(3-4): paper Nr. 212.

NAM, 2016. Technical Addendum to the Winningsplan Groningen 2016: Production, Subsidence Induced Earthquakes and Seismic Hazard and Risk Assessment in the Groningen Field. Technical Report. Report No. EP201603238413. Nederlandse Aardolie Maatschappij B.V. (Assen).

Nielsen, S., Spagnuolo, E., Smith, S.A.F., Violay, M., Di Toro, G. \& Bistacchi, A., 2016. Scaling in natural and laboratory earthquakes. Geophysical Research Letters 43(4): 1504-1510.

Orlic, B. \& Wassing, B.B.T., 2013. A study of stress change and fault slip in producing gas reservoirs overlain by elastic and viscoelastic caprocks. Rock Mechanics and Rock Engineering 46(3): 421-435.

Pennington, W.D., Davis, S.D., Carlson, S.M., DuPree, J. \& Ewing, T.E., 1986. The evolution of seismic barriers and asperities caused by the depressuring of fault planes in oil and gas fields of South Texas. Bulletin of the Seismological Society of America 76(4): 939-948.

Plotnikova, L.M., Nurtaev, B.S., Grasso, J.R., Matasova, L.M. \& Bossu, $\boldsymbol{R}$. (1996). The character and extent of seismic deformation in the focal zone of Gazli earthquakes of 1976 and 1984, M >7.0. In: Knoll, P. \& Kowalle, G. (eds): Induced seismic events. Birkhäuser (Basel): 377-387.

Pratt, W.E. \& Johnson, D.W., 1926. Local subsidence of the Goose Creek Oil Field. The Journal of Geology 34(7, part 1): 577-590.

Reches, Z., 1999. Mechanisms of slip nucleation during earthquakes. Earth and Planetary Science Letters 170(4): 475-486.

Roest, J.P.A. \& Kuilman, W. 1994. Geomechanical analysis of small earthquakes at the Eleveld gas reservoir. Proceedings of the International Conference Eurock '94, Delft, Netherlands. . Balkema (Rotterdam): 573580.

Samuelson, J. \& Spiers, C. J., 2012. Fault friction and slip stability not affected by Co2 storage: evidence from short-term laboratory experiments on North Sea reservoir sandstones and caprocks. International Journal of Greenhouse Gas Control 11, Supplement: S78-S90.

Segall, $P_{.}, 1985$. Stress and subsidence resulting from subsurface fluid withdrawal in the epicentral region of the 1983 Coalinga Earthquake. Journal of Geophysical Research: Solid Earth 90(B8): 6801-6816.

Segall, P., 1989. Earthquakes triggered by fluid extraction. Geology 17(10): 942946.

Segall, P., Grasso, J.R. \& Mossop, A., 1994. Poroelastic stressing and induced seismicity near the Lacq gas field, southwestern France. Journal of Geophysical Research 99(B8): 15,423-15,438.

Spetzler, J. \& Dost, B., 2017. Probabilistic seismic hazard analysis for induced earthquakes in Groningen, Update June 2017. Royal Netherlands Meteorological Institute (De Bilt).

Spiers, C.J., Hangx, S.J.T. \& Niemeijer, A.R., 2017. New approaches in experimental research on rock and fault behaviour in the Groningen gasfield. Netherlands Journal of Geosciences / Geologie en Mijnbouw, this issue.

Tembe, S., Lockner, D.A. \& Wong, T., 2010. Effect of clay content and mineralogy on frictional sliding behavior of simulated gouges: binary and ternary mixtures of quartz, illite, and montmorillonite. Journal of Geophysical Research: Solid Earth 115(B3): B03416. Doi: 10.1029/2009JB006383. 
Tenthorey, E. \& Cox, S.F., 2006. Cohesive strengthening of fault zones during the interseismic period: an experimental study. Journal of Geophysical Research: Solid Earth 111(B9): B09202. Doi: 10.1029/2005JB004122.

TNO, 2013. Toetsing van de bodemdalingsprognoses en seismische hazard ten gevolge van gaswinning van het Groningen veld. Eindrapport. Report No. R11953. TNO, (Utrecht).

Uenishi, K. \& Rice, J.R., 2003. Universal nucleation length for slip-weakening rupture instability under nonuniform fault loading. Journal of Geophysical Research 108 (B1): 2042. Doi: 10.1029/2001JB001681.

Urai, J.L., Kettermann, M., Abe, S. \& Virgo, S., 2016. Aspects of fault zones around the Rotliegend reservoirs and the possible effects of salt in the fault zones on rates of seismicity in these zones. Report of a short project in April-May 2016,,supervised by State Supervision of Mines, Ministerie van Economische Zaken. IGEM, EMR and RWTH Aachen University (Aachen).

Van den Bogert, P.A.J., 2015. Impact of various modelling options on the onset of fault slip and fault slip response using 2-dimensional finite-element modelling. Restricted, Report No. SR.15.11455. Shell Global Solutions International B.V. (Rijswijk).

Van Eijs, R.M.H.E., 2015. Neotectonic stresses in the Permian Slochteren Formation of the Groningen Field. KNMI Scientific Report. Report No. EP201510210531. NAM (Assen).

Van Thienen-Visser, K., Nepveu, M. \& Hettelaat, J., 2012. Deterministische hazard analyze voor geïnduceerde seismiciteit in Nederland. Report No. R10198. TN0 (Utrecht). (Update seismic hazard)

Van Thienen-Visser, K., Pruiksma, J.P. \& Breunese, J.N., 2015. Compaction and subsidence of the Groningen gas field in the Netherlands.
Proceedings of the International Association of Hydrological Sciences 372: 367-373.

Verweij, J.M., Simmelink, H.J., Underschultz, J. \& Witmans, N., 2012. Pressure and fluid dynamic characterisation of the Dutch subsurface. Netherlands Journal of Geosciences / Geologie en Mijnbouw 91(4): 465-490.

Wassing, B.B.T., Van Wees, J.D., \& Fokker, P.A., 2014. Coupled continuum modeling of fracture reactivation and induced seismicity during enhanced geothermal operations. Geothermics 52: 153-164.

Wassing, B.B.T., Buijze, L. \& Orlic, B., 2016. Modelling of fault reactivation and fault slip in producing gas fields using a slip-weakening friction law. 50th Rock Mechanics Symposium, Houston, Texas. ARMA 16-658. Proceedings.

Wassing, B.B.T., Buijze, L. \& Orlic, B., 2017. Fault reactivation and fault rupture in producing gas fields with elastic and visco-elastic caprocks. 51st Rock Mechanics Symposium, San Francisco, California. ARMA 17-355. Proceedings.

Wentinck, R.H., 2015. Induced seismicity in the Groningen field - statistical assessment of tremors along faults in a compacting reservoir. Report No. SR.15.11335. Shell Global Solutions International B.V. (Rijswijk).

Yasuhara, H., Marone, C. \& Elsworth, D., 2005. Fault zone restrengthening and frictional healing: the role of pressure solution. Journal of Geophysical Research: Solid Earth 110: B06310. Doi: 10.1029/2004jb003327.

Yerkes, R.F. \& Castle, R.O., 1976. Seismicity and faulting attributable to fluid extraction. Engineering Geology 10(2-4): 151-167.

Zbinden, D., Rinaldi, A.P., Urpi, L. \& Wiemer, S., 2017. On the physics-based processes behind production-induced seismicity in natural gas fields. Journal of Geophysical Research: Solid Earth 122(5): 3792. Doi: 10.1002/2017jb014003. 